\title{
VERA-Grizzly Ex-Core Calculations: Watts Bar Unit 1 Cycles 1-2
}

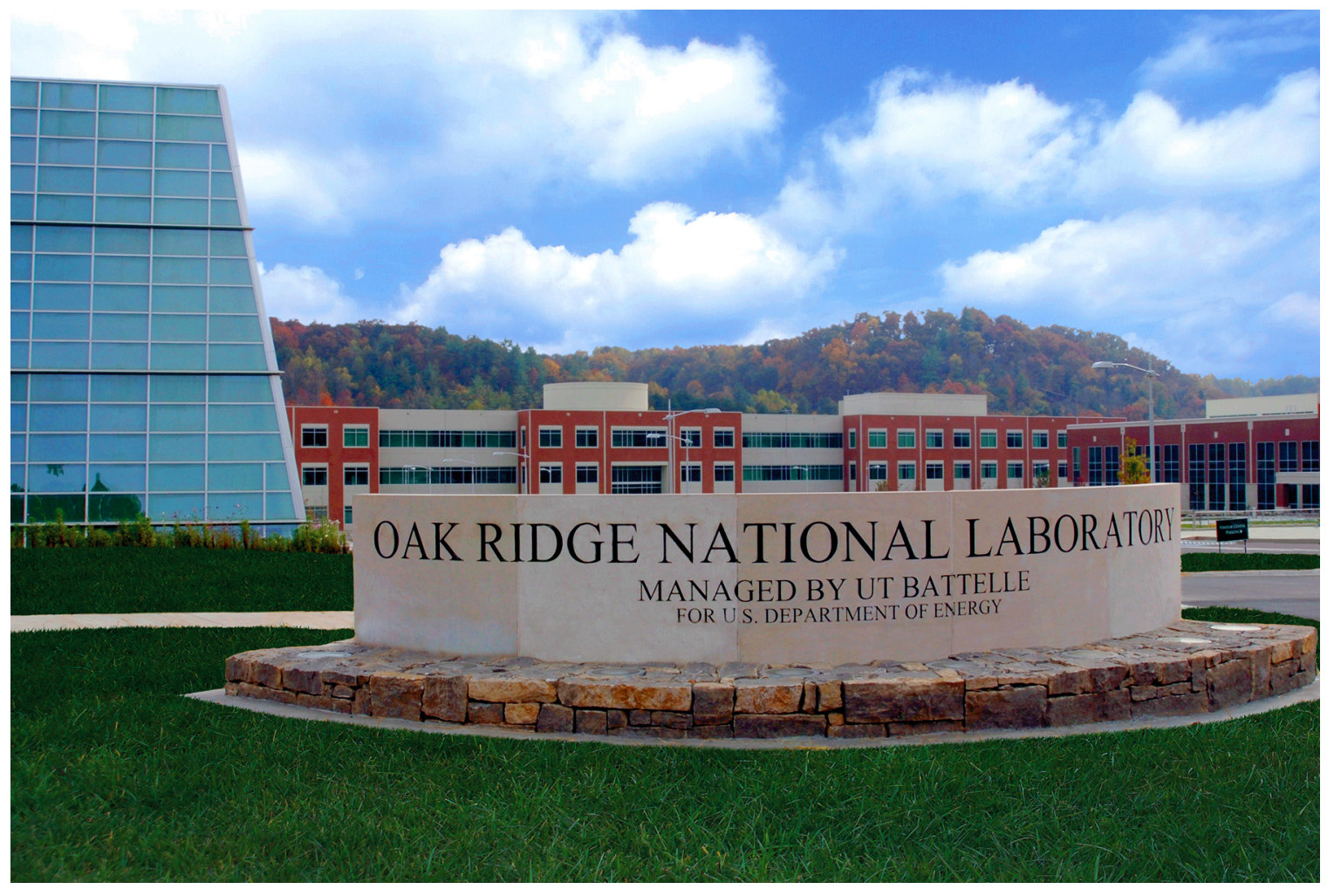

\section{Eva Davidson}

Mehdi Asgari

Mark Baird

Amani Cheniour

Benjamin Collins

Andrew Godfrey

Yann Le Pape

Tara Pandya

Benjamin Spencer

September 2021

\section{OAK RIDGE \\ National Laboratory}




\section{DOCUMENT AVAILABILITY}

Reports produced after January 1, 1996, are generally available free via US Department of Energy (DOE) SciTech Connect.

Website: www.osti.gov/

Reports produced before January 1, 1996, may be purchased by members of the public from the following source:

National Technical Information Service

5285 Port Royal Road

Springfield, VA 22161

Telephone: 703-605-6000 (1-800-553-6847)

TDD: $703-487-4639$

Fax: 703-605-6900

E-mail: info@ntis.gov

Website: http://classic.ntis.gov/

Reports are available to DOE employees, DOE contractors, Energy Technology Data Exchange representatives, and International Nuclear Information System representatives from the following source:

Office of Scientific and Technical Information

PO Box 62

Oak Ridge, TN 37831

Telephone: 865-576-8401

Fax: 865-576-5728

E-mail: report@osti.gov

Website: http://www.osti.gov/

This report was prepared as an account of work sponsored by an agency of the United States Government. Neither the United States Government nor any agency thereof, nor any of their employees, makes any warranty, express or implied, or assumes any legal liability or responsibility for the accuracy, completeness, or usefulness of any information, apparatus, product, or process disclosed, or represents that its use would not infringe privately owned rights. Reference herein to any specific commercial product, process, or service by trade name, trademark, manufacturer, or otherwise, does not necessarily constitute or imply its endorsement, recommendation, or favoring by the United States Government or any agency thereof. The views and opinions of authors expressed herein do not necessarily state or reflect those of the United States Government or any agency thereof. 
Nuclear Energy Advanced Modeling and Simulation

VERA-Grizzly Ex-core Calculations:Watts Bar Unit 1 Cycles 1-2

\author{
Eva Davidson \\ Mehdi Asgari \\ Mark Baird \\ Amani Cheniour \\ Benjamin Collins \\ Andrew Godfrey \\ Yann Le Pape \\ Tara Pandya \\ Benjamin Spencer
}

September 2021

Prepared by

OAK RIDGE NATIONAL LABORATORY

Oak Ridge, TN 37831-6283

managed by

UT-Battelle LLC

for the

US DEPARTMENT OF ENERGY

under contract DE-AC05-00OR22725 



\section{CONTENTS}

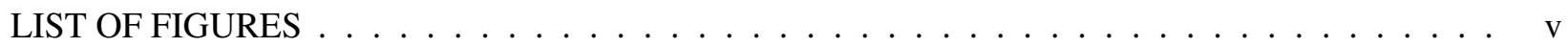

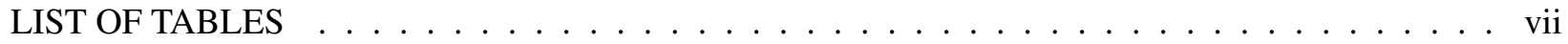

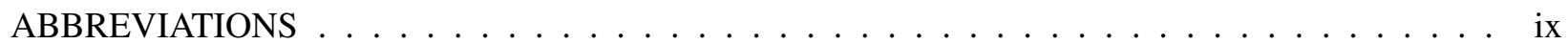

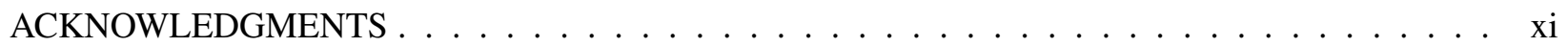

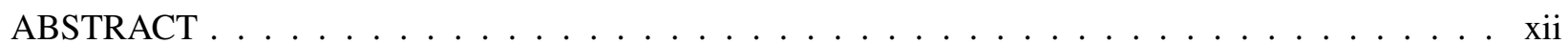

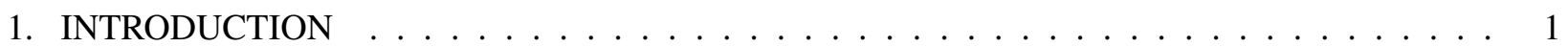

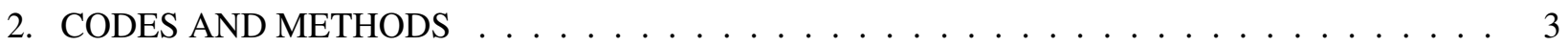

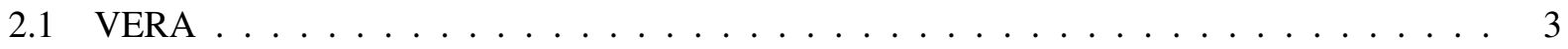

2.2 Grizzly Code for Modeling Concrete Degradation . . . . . . . . . . . . . . . . . 4

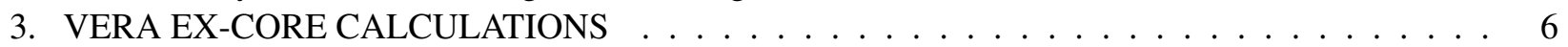

3.1 Watts Bar Unit 1 models for Cycles 1 and $2 \ldots \ldots \ldots \ldots$

3.1 .1 Neutron Calculations with CADIS . . . . . . . . . . . . . . . 8

3.1 .2 Neutron Calculations with FW-CADIS . . . . . . . . . . . . . . . . 10

3.2 Computing Resources and Feedback on Code Performance . . . . . . . . . . . . . . . 17

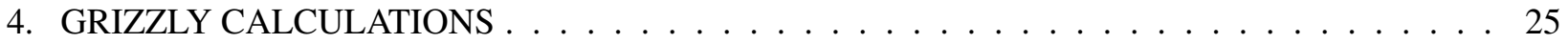

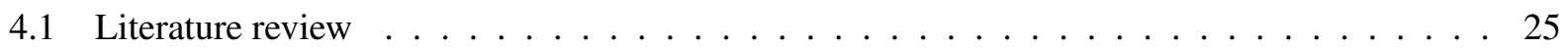

4.2 Transferring Fluence from VERA to Grizzly . . . . . . . . . . . . . . . . . . 28

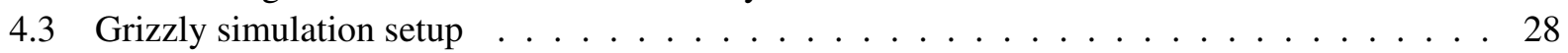

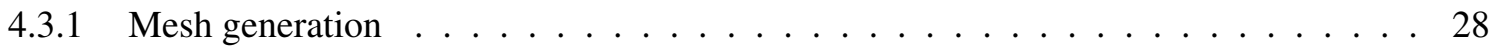

4.3 .2 Elastic properties . . . . . . . . . . . . . . . . . . . . . . . 29

4.3.3 radiation-induced volumetric expansion (RIVE) model . . . . . . . . . . . . . . 29

4.3 .4 Damage models . . . . . . . . . . . . . . . . . . . . 31

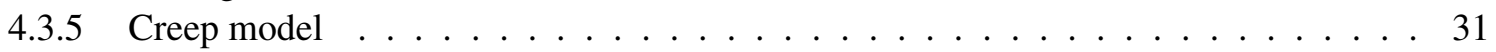

4.4 Results . . . . . . . . . . . . . . . . . . . . . 33

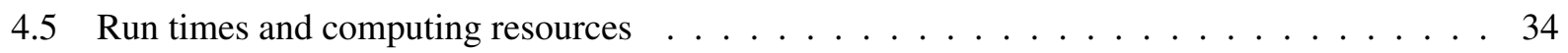

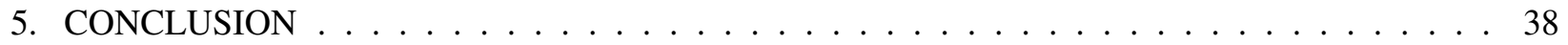

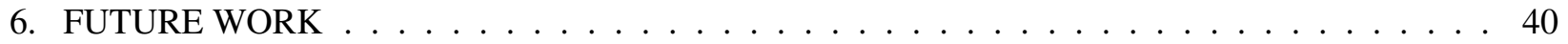

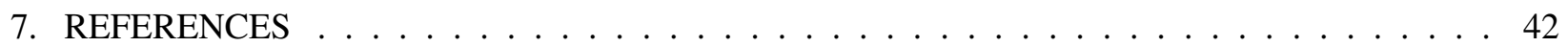





\section{LIST OF FIGURES}

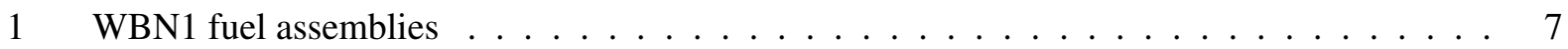

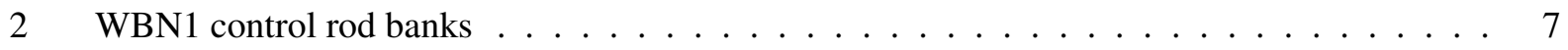

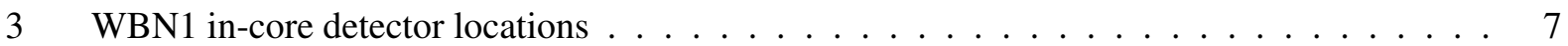

4 WBN1 VERA model. [Note: $\mathrm{x}$-axis in $\mathrm{cm}$ and $\mathrm{y}$-axis in $\mathrm{cm}$ ] . . . . . . . . . . . . . . 9

5 Fission source strength as a probability distribution function (PDF) at BOC and EOC passed from MPACT to Shift for WBN1 Cycle $1 \ldots \ldots \ldots \ldots$. . . . . . . . 11

6 Fission source strength as a PDF at BOC and EOC passed from MPACT to Shift for

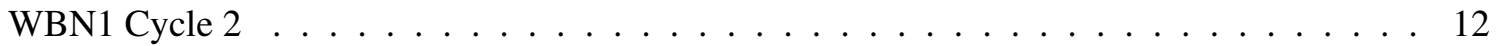

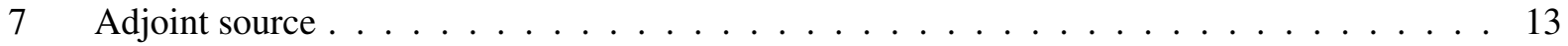

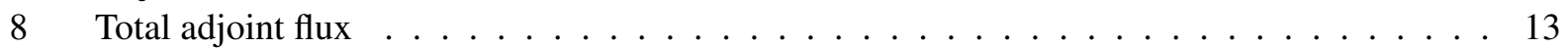

9 Group-wise adjoint flux . . . . . . . . . . . . . . . . . . . . . 14

10 WBN1 Cycle 1 vessel fluence and variance as seen in VERAView. . . . . . . . . . . . . . 15

11 WBN1 Cycle 2 vessel fluence and variance as seen in VERAView. . . . . . . . . . . . . . 15

12 Relative error in the flux in the $\mathrm{z}$ mesh extending from 162.84 to $203.55 \mathrm{~cm}$ for WBN1

Cycles 1 and 2 at the first statepoint . . . . . . . . . . . . . . . 17

13 Relative error in the flux in the $\theta$ mesh extending from 0.698 to 0.785 radians for WBN1

Cycles 1 and 2 at the first statepoint. . . . . . . . . . . . . . . . . . 18

14 Groupwise adjoint flux generated using FW-CADIS that shows the importance of particles to the region of interest for Cycle $1 \ldots \ldots \ldots$. . . . . . . . . . 19

15 WBN1 Cycle 2 results for one statepoint with FW-CADIS with a larger mesh tally _. . . . 20

16 WBN1 Cycle 2 results for one statepoint with FW-CADIS and a larger mesh tally and with $\mathrm{P}_{1}$ order for scattering in deterministic calculation . . . . . . . . . . . . . 21

17 Group 6 adjoint flux $(0.1013<\mathrm{E}<24.18 \mathrm{keV})$ for FW-CADIS case with $\mathrm{P}_{1}$ scattering . . . . . 21

18 WBN1 Cycle 2 results for one statepoint with FW-CADIS and 4 billion particle histories . . 22

19 Representative mesh and geometry generated to simulate radiation-induced degradation in the CBS. . . . . . . . . . . . . . . . . . . . . . . . . . 29

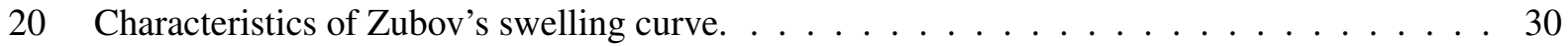

21 Example fluence map $\left(\mathrm{n} / \mathrm{cm}^{2}\right.$ for $\left.E_{n}>0.1 \mathrm{MeV}\right)$ in a clipped domain of the CBS. . . . . 34

22 Example clipped damage fields taken from Case 3 at maximum fluence $2.5 \times 10^{19} \mathrm{n} / \mathrm{cm}^{2}$. . . 35

23 Damage (left axis) and fluence $\left(\mathrm{n} / \mathrm{cm}^{2}\right.$ for $\left.E_{n}>0.1 \mathrm{MeV}\right)$ (right axis) evolution with depth in the CBS. . . . . . . . . . . . . . . . . . . 36

24 Clipped damage fields at maximum fluence $3.6 \times 10^{19} \mathrm{n} / \mathrm{cm}^{2}\left(E_{n}>0.1 \mathrm{MeV}\right)$ and approximately 40 years of irradiation. . . . . . . . . . . . . . . . 37 



\section{LIST OF TABLES}

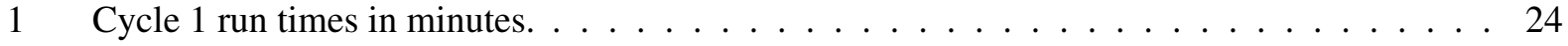

2 Cycle 2 run times in minutes. . . . . . . . . . . . . . . . . . . . . 24

3 Damage model parameters used in Grizzly . . . . . . . . . . . . . . . . . . . 32

4 Logarithmic creep model parameters from Torrenti and Le Roy [2018] and Kommendant et al. [1976] . . . . . . . . . . . . . . . . . . . . . 32

5 Elastic term and irrecoverable basic creep model parameters used in Grizzly . . . . . . . . . 33

6 Run times by case. . . . . . . . . . . . . . . . . . . 36 



\section{ABBREVIATIONS}

$\begin{array}{ll}\text { ASR } & \text { alkali-silica reaction } \\ \text { BOC } & \text { beginning of cycle } \\ \text { CADIS } & \text { Consistent Adjoint Driven Importance Sampling } \\ \text { CASL } & \text { Consortium for Advanced Simulation of Light Water Reactors } \\ \text { CBS } & \text { concrete biological shield } \\ \text { CTF } & \text { COBRA-TF } \\ \text { EOC } & \text { end of cycle } \\ \text { FW-CADIS } & \text { Forward-Weighted CADIS } \\ \text { HPC } & \text { high-performance computing } \\ \text { IFBA } & \text { integral fuel burnable absorber } \\ \text { LWR } & \text { light-water reactor } \\ \text { MC } & \text { Monte Carlo } \\ \text { MOOSE } & \text { Multiphysics Object Oriented Simulation Environment } \\ \text { NEAMS } & \text { Nuclear Energy Advanced Modeling and Simulation } \\ \text { ORNL } & \text { Oak Ridge National Laboratory } \\ \text { PDF } & \text { probability distribution function } \\ \text { PWR } & \text { pressurized water reactor } \\ \text { RIVE } & \text { radiation-induced volumetric expansion } \\ \text { RPV } & \text { reactor pressure vessel } \\ \text { TVA } & \text { Tennessee Valley Authority } \\ \text { VERA } & \text { Virtual Environment for Reactor Applications } \\ \text { VR } & \text { variance reduction } \\ \text { WABA } & \text { wet annular burnable absorber } \\ \text { WBN1 } & \text { Watts Bar Nuclear Plant Unit 1 }\end{array}$





\section{ACKNOWLEDGMENTS}

This research made use of Idaho National Laboratory (INL) computing resources which are supported by the Office of Nuclear Energy of the US Department of Energy and the Nuclear Science User Facilities under Contract No. DE-AC07-05ID14517. The authors would especially like to thank the INL High-Performance Computing Team for their efforts in supporting these calculations on Sawtooth and Lemhi. 


\begin{abstract}
The critical structures that comprise light-water reactor (LWR) nuclear power plants are subjected to operating environments that can challenge their integrity. Structures in close proximity to the reactor core, such as the reactor pressure vessel (RPV) and the biological shield wall, are subjected to high levels of radiation emanating from the core, as well as elevated temperatures. As the US fleet of operating LWRs ages, the effects of these operating environments on the integrity of these structures must be considered to ensure their continued safe operation. Extending the lifetime of commercial reactors and maintaining the aging reactor fleet require accurate prediction of the exposure of ex-core components to neutron and photon radiation. In particular, concrete degradation studies must be performed to evaluate the safety and long-term operation of reactors with lifetime extensions. The concrete reactor bioshield is important for providing radiological protection during operation and must last for the entire lifetime of the reactor. Recent interest in lifetime extensions furthers the need to accurately simulate concrete material degradation in the reactor bioshield. As a result of this need, the Nuclear Energy Advanced Modeling and Simulation (NEAMS) program has funded this study to couple its tools, Virtual Environment for Reactor Applications (VERA) and Grizzly. VERA allows users to set up models to calculate time-dependent and fully coupled solutions (with thermal feedback) for ex-core quantities of interest such as vessel and coupon fluence and detector responses for multiple statepoints and cycles. Grizzly is a finite-element application based on the Multiphysics Object Oriented Simulation Environment (MOOSE) framework that is used to enable aging materials calculations. This report highlights the work performed to calculate the fluence in the vessel and concrete for Watts Bar Nuclear Plant Unit 1 (WBN1) Cycles 1 and 2. The fluences obtained from VERA were successfully transferred to Grizzly using a Python script. Four simulations were run with Grizzly: (1) the Mazars model with the initial Young's modulus being the instantaneous modulus, (2) the Mazars model with the initial Young's modulus being the delayed modulus, (3) the Mazars model with the initial Young's modulus being the delayed modulus with the addition of the effects of micro-damage caused by irradiation, and (4) the Mazars model with the initial Young's modulus being the instantaneous modulus, and with the addition of micro-damage and creep. Details regarding the methods used to obtain the fluence and the statistical errors associated with the VERA Monte Carlo Shift calculations are discussed in greater detail in this report. The results obtained from the four Grizzly models are also presented in this report.
\end{abstract}




\section{INTRODUCTION}

There is a great need to accurately predict and quantify neutron and photon exposures to ex-core components using advanced modeling and simulation tools as utilities owning nuclear power plants submit the subsequent license renewal (SLR) applications for their LWR fleet. The integrity of the RPV, concrete biological shield (CBS) (also known as the bioshield), nozzles, and various other ex-core components is crucial to lifetime extensions. The radiation exposure to these structures must be analyzed in greater detail to facilitate these lifetime extensions-especially the bioshield, which is the focus of this report.

It is important to perform material degradation studies on concrete structures because they are critical for the safety and long-term operation of reactors: the CBS protects equipment and personnel from radiation during operation. Furthermore, concrete structures represent major capital investment in nuclear power plants despite being passive components. For some reactors, the CBS also functions as a physical support to reactor systems. This support function needs to be ensured during normal operations as well as accident scenarios. After several decades of operation, the bioshield is exposed to high-energy radiation, so it is necessary to study whether fluence levels are exceeding the limits considered detrimental for the concrete's structural integrity. It may also be necessary to establish or revise these limits through detailed analysis to gain a much better understanding of irradiation-induced degradation of concrete structures using advanced modeling and simulation tools. Such conditions are reactor-specific, and they occur at different times, depending on a given reactor's operation history and design. For license applications involving lifetime extensions, it is mandatory to assess the potential effects of prolonged irradiation on structures and components such as concrete.

Unlike steel components, concrete structures are built with local constituents (cement, sand, coarse aggregates) to avoid prohibitive transportation costs. Thus, the tolerance against irradiation of the concrete biological shields may vary greatly among the 96 nuclear power plants forming the current US LWR fleet. Irradiation-induced degradation is achieved mainly by amorphization-induced expansions, which are generally referred to as RIVE of the silicated minerals present in the aggregates. The neutron irradiation-induced expansion varies from one rock-forming mineral to another: well-framework structured silicates (e.g., quartz and feldspars) exhibit higher swelling than chained (e.g., pyroxenes) or isolated silicates (e.g., garnet). Silicates make up nearly $90 \%$ of the Earth's crust. Other common minerals present in construction aggregates are carbonates found in limestone, for example. Irradiated carbonates exhibit only very minor expansions. The rate and amplitude of radiation-induced expansion vary considerably between the aggregate-forming minerals and can subsequently cause cracking in irradiated-aggregates, leading to a loss of mechanical properties. In addition, the overall expansion of the aggregates creates important mechanical energy storage in the cement paste. The stored energy dissipation occurs by viscous relaxation cracking, contributing to further loss of the concrete's structural properties. Therefore, the interactions among the degradation mechanisms involved during concrete irradiation are quite complex, time-dependent, highly nonlinear, and highly dependent on the mineralogy of the concrete aggregates.

The radiation-induced damage of concrete is observed on test reactors (under accelerated conditions) for fluence levels exceeding $\approx 10^{19} \mathrm{n} / \mathrm{cm}^{2}$ at neutron energies above $0.1 \mathrm{MeV}$. Depending on operation history, that damage threshold will be reached at varied stages of a commercial nuclear plant's life. In LWR bioshields, the RIVE-induced stress state is highly three-dimensional because of the fluence gradient caused by neutron attenuation. Hence, damage is mainly governed by structural constraints caused by biaxial compression loading near the reactor cavity. The main question to assess regarding structural performance is the 
depth of irradiation-induced damage in the CBS at the end of life. If damage extends beyond the location of the steel reinforcement, then beyond-design conditions will occur, requiring further analysis for extended operation or lifetime extension license renewals.

This work aims to take advantage of the advanced modeling and simulation tools funded by the NEAMS program to demonstrate their ability to perform the calculations necessary to inform concrete material degradation, and subsequently, lifetime extensions. As a first step in demonstrating the capability of NEAMS tools to perform calculations of this magnitude, a simple concrete model was set up without any steel reinforcements using the proprietary WBN1 reactor models (Godfrey et al. [2016]) to run a multiphysics calculation. The calculation involved neutron in-core and ex-core radiation transport with thermal feedback using VERA (Turner et al. [2016]), and then a material degradation calculation using Grizzly (Spencer et al. [2016]). The WBN1 neutronics models have been benchmarked against plant data (Godfrey et al. [2016]) for 18 years of plant operation for measured critical boron concentrations, control bank reactivity worths, isothermal temperature coefficients, and in-core neutron flux distributions. The benchmarking exercise showed excellent agreement of these parameters as calculated by VERA and the plant data. Therefore, there is confidence that these WBN1 VERA models are accurate and can be used for this study.

Details and steps taken to perform the calculations outlined above are provided in the following sections. The methods used in VERA and Grizzly to perform the fluence calculations are discussed in Section 2.; the VERA model, calculations and the outputs are discussed in Section 3.; the Grizzly model and the material degradation analysis are provided in Section 4.; the concluding remarks are in Section 5.; and the implications of the findings and potential future work are listed in Section 6. 


\section{CODES AND METHODS}

\subsection{VERA}

VERA development began 11 years ago under the Consortium for Advanced Simulation of Light Water Reactors (CASL) program, with significant emphasis on the ability of the codes to run and scale efficiently on high-performance computing (HPC) clusters. The software suite is now funded through NEAMS for LWR applications after the CASL program ended. VERA [Kochunas et al. [2017]] contains codes that use deterministic, Monte Carlo (MC) and hybrid deterministic/MC radiation transport methods. Users define the reactor core and multiphysics input parameters through the VERAIn (Palmtag and Godfrey [2015]) ASCII interface. VERA allows users to perform high-fidelity in-core radiation transport with temperature feedback using MPACT [Collins and et al. [2016]], a deterministic neutron transport code, and COBRATF (CTF) [Avramova [2009]], a subchannel thermal hydraulics code. MPACT uses two-dimensional (2D) method of characteristics (MOC) and the one-dimensional (1D) simplified $\mathrm{P}_{\mathrm{N}}$ method to calculate the threedimensional (3D) whole-core, pin-resolved neutron flux, using coarse mesh finite difference (CMFD) (Godfrey et al. [2016]). Fuel depletion is performed through the MPACT and ORIGEN [Wieselquist et al. [2020]] coupling that allows MPACT to perform the fuel depletion and decay in approximately 7.5 million unique regions in the WBN1 reactor core (Godfrey et al. [2016]). For optimal use of computational resources and run times, only the isotopes important for LWR core physics (263 nuclides) are tracked while preserving total energy production, activity, mass, and macroscopic cross sections (Godfrey et al. [2016]). CTF uses a transient two-fluid and three-field (liquid film, liquid drops and vapor) modeling approach to determine the thermodynamic conditions in each coolant channel. It accounts for cross-flow caused by turbulentmixing, void drift, and lateral pressure gradient, and it also captures rod-to-fluid heat transfer, inter-phase heat and mass transfer, wall and inter-phase drag, and spacer-grid-droplet breakup (Godfrey et al. [2016]). The deterministic MPACT/CTF calculation provides the source for the follow on fixed-source hybrid deterministic/MC calculation with in-core and ex-core neutron transport using the Shift MC code (Pandya et al. [2020], Davidson et al. [2021]). Shift performs this fixed-source hybrid calculation on the full geometry (both in-core and ex-core regions) to calculate ex-core quantities of interest, such as fluence.

The Denovo deterministic transport code (Evans et al. [2010]) enables Shift to take advantage of variance reduction (VR) methods such as Consistent Adjoint Driven Importance Sampling (CADIS) and ForwardWeighted CADIS (FW-CADIS) (Wagner and Haghighat [1998], Wagner et al. [2014]), within VERA for efficient calculation of ex-core quantities. In CADIS mode, which is the default VR method in VERA, the adjoint flux is first calculated. The adjoint flux is a measure of a particle's importance to the ex-core quantity of interest and indicates the contribution of a particle at a given location and in an energy group to a response. The adjoint is then used to calculate space- and energy-dependent VR parameters in the form of weight windows and a biased/optimized neutron source. The biased neutron source enables Shift to preferentially sample source particles that are more important to the optimization region. The consistent biased source and weight windows increase the number of particle histories that will ultimately reach the region of interest and contribute to the response while reducing the number of unimportant particles that are unlikely to contribute. A fair game is always ensured in the random sampling process so that the ex-core response (solution) does not have a statistical bias (Davidson et al. [2021]). Together, these parameters can significantly accelerate the subsequent Shift MC calculation by prioritizing the transport of only particles that will contribute to the desired tally. The adjoint source is located at the ex-core tally of interest, in this case the CBS. For the work presented in this report, a response that is uniform in energy in the meshed 
bioshield is used for the adjoint source. The resulting adjoint function-the importance of particles to the bioshield-drops off rapidly between the edge and the center of the core. These methods are explained in greater detail in Pandya et al. [2020] and Davidson et al. [2021].

MPACT passes the spatially dependent fission source from the in-core radiation transport calculation to Shift. Shift samples this in-core fission source distribution for the neutron source locations. However, Shift must determine the neutron source energies. It is assumed that the neutrons are born from fission of four nuclides- ${ }^{235} \mathrm{U},{ }^{238} \mathrm{U},{ }^{239} \mathrm{Pu}$, and ${ }^{241} \mathrm{Pu}$. These four nuclides are the most prominent fission neutron producers in an LWR. MPACT sends the fission source strength from each of these four nuclides in each fuel region to Shift after every state point in a fuel cycle. The source strengths from all other nuclides are ignored since they are negligible for the LWR applications under analysis. More details regarding this can be found in Davidson et al. [2021]. This source strength is then used to sample for the neutron source energies from the Watt spectrum of one of the four corresponding source nuclides.

Finally, Shift calculates the flux at the RPV and bioshield and passes this quantity back to MPACT, which then performs a time-integration to keep track of the fluence in these regions. This fluence is then passed off to Grizzly in a loosely coupled manner using a post-processing script that overlays the fluence on a grid in an Exodus file. This Exodus file is then used as input to Grizzly for material degradation studies. More details regarding this loose coupling are discussed in Section 4.

\subsection{Grizzly Code for Modeling Concrete Degradation}

Grizzly is a finite element code for simulation of degradation processes and their effects on nuclear power plant components and structures (Spencer et al. [2021]). For LWRs, Grizzly includes capabilities for modeling reactor pressure vessels and reinforced concrete structures such as containment vessels and biological shield walls. There are multiple mechanisms of potential concern for degradation in concrete structures. Grizzly includes models for RIVE and alkali-silica reaction (ASR), both of which have been identified as high priority areas for research because each has the potential to be an issue of concern, and each has notable knowledge gaps as discussed in Graves et al. [2014].

Most degradation mechanisms in concrete are influenced by a combination of the local temperature, moisture content, and stresses. Therefore, it is essential for a simulation tool to be able to model the coupled phenomena of thermal and moisture transport and mechanical deformation. Grizzly is based on the opensource MOOSE framework (Permann et al. [2020]), which provides an environment specifically tailored for developing multiphysics simulation capabilities. MOOSE is written in $\mathrm{C}++$ and has a modular, objectoriented design that makes it straightforward for implementing new physics models, and it also allows those models to interact with models for other physics. MOOSE uses the finite element method to solve the set of partial differential equations for these physics models in a tightly coupled manner and takes advantage of parallel high-performance computers.

Grizzly solves the field equations governing spatial and temporal variations in temperature, relative humidity, and displacement. Its RIVE and ASR models compute the extent of these reactions at local material points, along with the resulting volumetric strain and local damage. It also has models for stress-induced damage. Concrete is modeled with continuum elements, while reinforcing bars are modeled with line elements embedded in the concrete domain, which can be modeled in either 2D or 3D. Constraints are used to tie the nodes of the rebar elements to the continuum elements, which allows for the rebar mesh to be defined independently of the concrete mesh, facilitating the creation of complex models. 
Grizzly's reinforced concrete modeling capabilities have been developed to the point at which they have a reasonably complete set of the main features needed to model complex structures. Recent efforts have validated Grizzly models against laboratory-scale experiments with accelerated alkali-silica reactions (ASR) (Spencer et al. [2020]), and efforts are underway to expand this validation suite and demonstrate Grizzly's ability to model large-scale reinforced concrete structures subjected to ASR. 


\section{VERA EX-CORE CALCULATIONS}

The Tennessee Valley Authority (TVA) WBN1 is a Westinghouse four-loop pressurized water reactor (PWR) with a thermal power rating of 3,459 $\mathrm{MW}_{\text {th }}$ (Godfrey et al. [2016]). The reactor core consists of 193 Westinghouse $17 \times 17$ fuel assemblies (Figure 1). Cycle 1 contains Pyrex discrete absorbers, a type of burnable absorber, in the fresh fuel for power shaping and excess reactivity control (Godfrey et al. [2016]). Cycle 2 consists of combinations of integral fuel burnable absorber (IFBA) and wet annular burnable absorber (WABA) (Godfrey et al. [2016]).

Each fuel cycle in any LWR has a unique fuel loading pattern. The first cycle consists of all fresh fuel, and the fluence is expected to be the highest for the first cycle. After the first cycle, one third of the core is replaced with fresh fuel, and the other two-thirds of the core is shuffled to create a low-leakage core loading pattern in which fuel assemblies with the highest burnup are placed along the periphery of the core. LWR fuel assemblies stay in an LWR for three cycles (or three batches) in different positions as determined by the most optimal core loading pattern for each of the three cycles, after which they are removed from the core and placed in the spent fuel cooling pool.

Core reactivity is controlled by boron in the coolant (also the neutron moderator). This boron is continuously removed or diluted as the fuel depletes throughout the cycle (Godfrey et al. [2016]). There are eight control rod banks (Figure 2) consisting of 57 rod cluster control assemblies (RCCAs) with 24 rodlets in each RCCA in the WBN1 model (Godfrey et al. [2016]). The VERA model also includes in-core instruments that monitor the neutron flux in the reactor (Figure 3).

\subsection{Watts Bar Unit 1 models for Cycles 1 and 2}

VERA inputs for WBN1 Cycles 1 and 2 were set up previously to perform benchmarking calculations (Godfrey et al. [2016]). These models were used to generate VERA results for comparison against plant data for measured critical boron concentrations, control bank reactivity worths, isothermal temperature coefficients, and in-core neutron flux distributions (Godfrey et al. [2016]). The comparisons showed excellent agreement between VERA and the data provided by TVA, as discussed in Godfrey et al. [2016]. There is a high degree of confidence in the accuracy of the geometry set-up of VERA core models for WBN1 Cycles 1 and 2. Therefore, the same models were used to perform ex-core calculations for this milestone report.

Each cycle requires only one VERA input, and no additional user effort is required to model the core or fuel in great detail for the ex-core calculations to be performed by Shift (Pandya et al. [2020], Davidson et al. [2021]). The reactor's in-core region, along with the reactor vessel liner, RPV, air gap, bioshield liner, and concrete bioshield, are all defined in one VERA input for each cycle. The power history and burnup for the two cycles are omitted from this report for proprietary reasons. Figure 4 shows the VERA model set-up for WBN1 Cycles 1 and 2. The ex-core calculations were performed in Shift using CADIS with 1 billion particles per state point. There are 32 statepoints in Cycle 1 and 22 statepoints in Cycle 2.

It should be noted that the ex-core calculations in VERA using these WBN1 models required the use of some assumptions to run successfully with the VERA 4.3 release candidate (RC) 5. The following assumptions have been made in the neutronics model:

1. The bioshield inner radius was 257.70 and the outer extent was truncated at $350.00 \mathrm{~cm}$, because the variance in the flux (and subsequently the fluence closer to $350 \mathrm{~cm}$ in the bioshield) is very high 


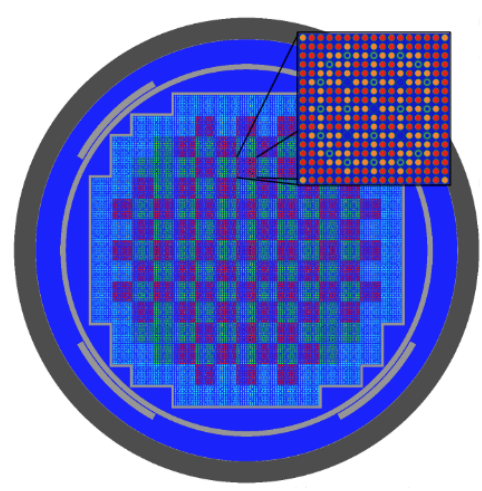

(a) Fuel assemblies in the in-core model

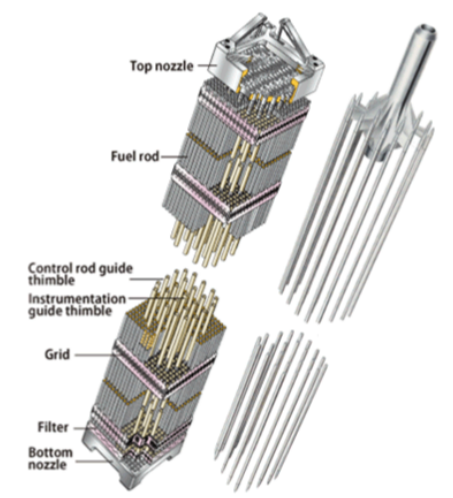

(b) Westinghouse 17x17 fuel assembly (Godfrey et al. [2016])

Figure 1. WBN1 fuel assemblies.

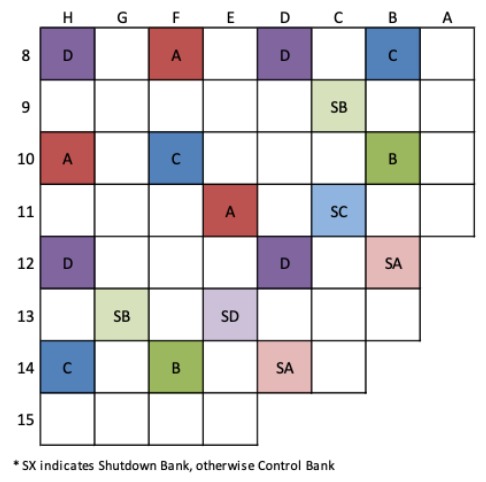

Figure 2. WBN1 control rod banks (Godfrey et al. [2016]).

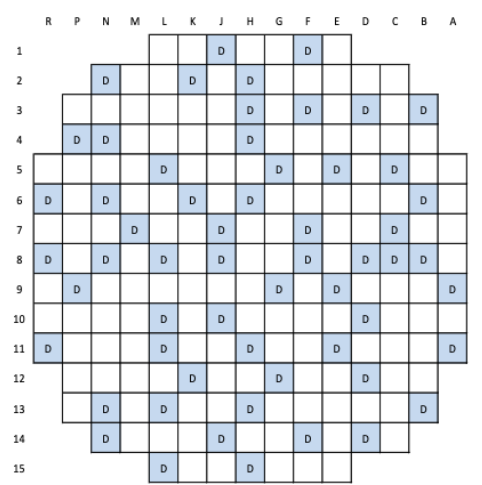

Figure 3. WBN1 in-core detector locations (Godfrey et al. [2016]). 
( $>20 \%$ ), even while running with CADIS and 1 billion particles. The true thickness of the bioshield at WBN1 is unknown.

2. The bioshield liner thickness is assumed to extend from 257.70 to $258.20 \mathrm{~cm}$ since the true thickness is unknown.

3. The concrete composition in the ex-core model was obtained from R. J. McConn Jr. et al. [2011] for a generic Oak Ridge National Laboratory (ORNL) concrete composition. Previous calculations for ex-core detector responses were generated with ex-core models with this concrete and yielded good agreement with the plant data for detector responses (Gentry et al. [2020]).

4. Bugs being worked out in VERA 4.3RC5 (a development RC) required thermal feedback to be turned off during the fuel shuffling. While the impact might be minimal because the shuffling is performed at 0 power, this assumption is stated here, nevertheless. Thermal feedback was turned on during the depletion calculation for each cycle.

5. Thermal expansion was turned off during these ex-core transport calculations in VERA.

6. Moderator density and temperature changes in the downcomer region are not accounted for in the Shift ex-core transport because these parameters cannot currently be transferred from MPACT to Shift.

7. The depleted isotopics in each pin (unique pins) after each statepoint (depletion step) are currently not transferred from MPACT to Shift because the large memory requirements are prohibitive. Shift assumes that the pin compositions from the first statepoint stay the same for the entire cycle but uses the updated spatial fission distribution from MPACT after each depletion step to perform the neutron source location sampling. The neutron source energies are assumed to be from a Watt spectrum associated with one of the four nuclides discussed earlier $\left({ }^{235} \mathrm{U},{ }^{238} \mathrm{U},{ }^{239} \mathrm{Pu}\right.$, and $\left.{ }^{241} \mathrm{Pu}\right)$.

\subsubsection{Neutron Calculations with CADIS}

Neutron fixed-source calculations with CADIS were performed in VERA with 1 billion particles. The flux values in the reactor pressure vessel and out to the bioshield (see Figure 4) were tallied for neutron energies above $1 \mathrm{MeV}$. There are 10 equal axial meshes extending from the bottom of the core at $0.0 \mathrm{~cm}$ to the top of the core at $407.1 \mathrm{~cm}$. There are 72 equal theta bins. There are 31 radial bins of varying sizes. The radial mesh from 0 to $219.15 \mathrm{~cm}$ represents the region from the center of the core to the inner radius of the vessel liner. This data is not passed to Grizzly. The fluence in 30 radial bins from $219.15 \mathrm{~cm}$ to $350 \mathrm{~cm}$ is passed to Grizzly.

The first step was to run the Cycle 1 WBN1 model with VERA. As explained above, Cycle 1 consists of fresh fuel and can be visualized through ${ }^{235} \mathrm{U}$ and ${ }^{238} \mathrm{U}$ fission source distributions at beginning of cycle (BOC) (Figures 5a and 5c). The core does not have a fission source distribution for ${ }^{239} \mathrm{Pu}$ and ${ }^{241} \mathrm{Pu}$ at BOC. However, toward the end of Cycle 1, the fission source strengths from ${ }^{235} \mathrm{U}$ and ${ }^{238} \mathrm{U}$ decrease (Figure $5 \mathrm{~b}$ and 5d). More notably, the ${ }^{235} \mathrm{U}$ fissions shift toward the edge of the core, and fissions from ${ }^{241} \mathrm{Pu}$ (Figure 5f) tend to dominate in the assemblies toward the center of the core. Fissions from ${ }^{239} \mathrm{Pu}$ also contribute to the fission source strength at end of cycle (EOC) (Figure 5e).

After completion of the Cycle 1 VERA simulation, VERA Cycle 2 model and core loading configuration was achieved by providing fuel loading and shuffle input. The Cycle 2 core loading consists of about twothirds of burnt fuel from Cycle 1 and one-third of fresh fuel. This is apparent when visualizing the fission 


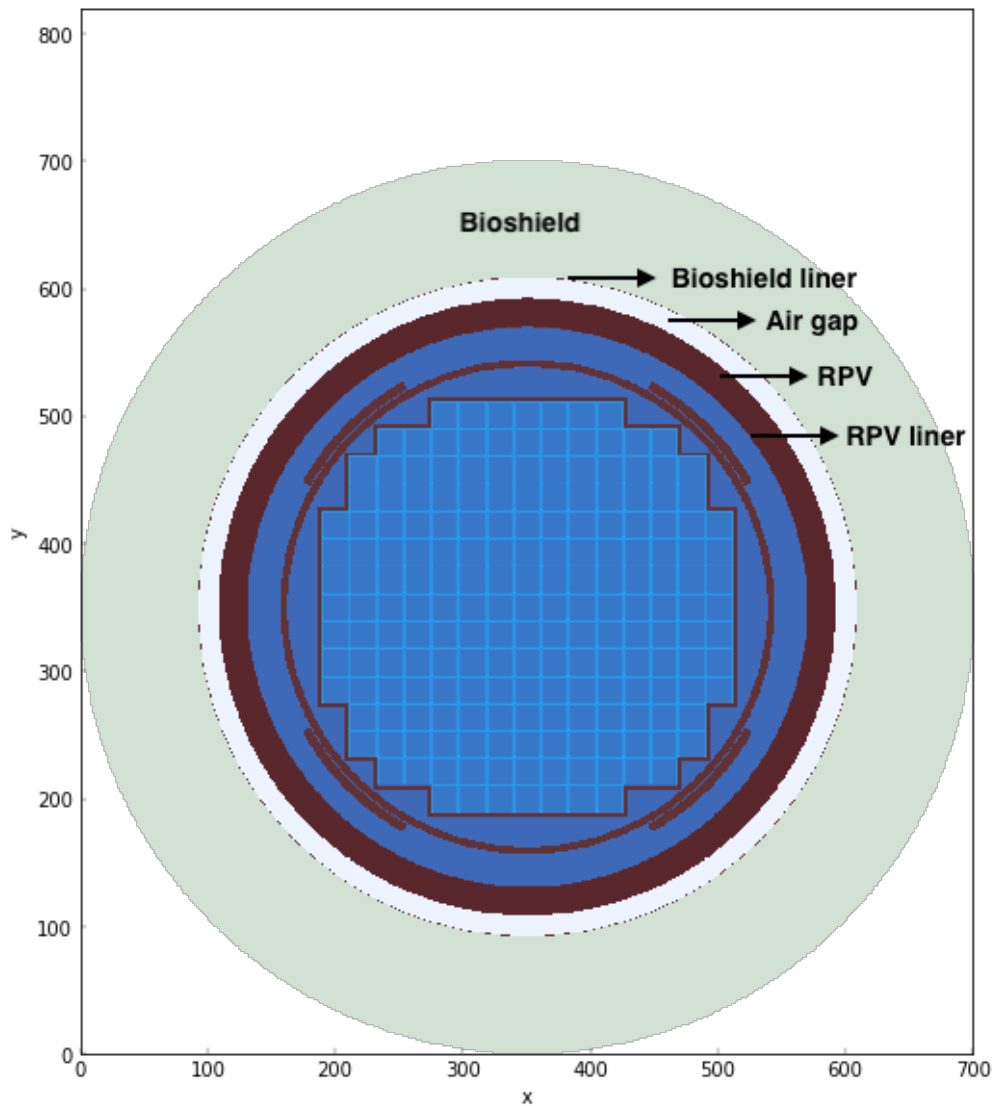

Figure 4. WBN1 VERA model. [Note: $x$-axis in $\mathrm{cm}$ and $y$-axis in $\mathrm{cm}$ ]. 
source distributions from ${ }^{235} \mathrm{U},{ }^{238} \mathrm{U},{ }^{239} \mathrm{Pu}$, and ${ }^{241} \mathrm{Pu}$ at BOC in Figure 6. The fresh fuel does not have fission source strengths from ${ }^{239} \mathrm{Pu}$ and ${ }^{241} \mathrm{Pu}$, and appears as solid blue squares in the core.

During each Shift simulation for Cycles 1 and 2, the adjoint flux is calculated to determine the region of importance for the problem that is set up. In this case, the region of importance starts at the RPV liner and ends at the outer diameter of the bioshield which is the adjoint source (Figure 7). The total adjoint flux shows the regions of the model important to the problem (Figure 8). Here, the neutrons closest to the periphery of the core and those scattering in the vessel and the bioshield are the most important to the problem. Therefore, these neutrons are more likely to be split and transported in Shift. Those neutrons in the center of the core are less likely to be transported and are preferentially killed without biasing the solution. The groupwise adjoint flux in Figure 9 shows that the thermal and epithermal neutrons from the center of the core are not as important to the tallies in the RPV and bioshield. However, the faster neutrons from the core are important to the tallies in the vessel and the bioshield. Therefore, these fast neutrons are more likely to be transported and more likely to contribute to the tallies set up in the ex-core region.

Figures 10 and 11 show the neutron fluence calculated by VERA. The maximum fluence is slightly below the axial midplane because the pin power peaking is the highest just below the axial midplane for more than half of the cycle before a double-hump-shaped profile forms and the axial pin power peaking shifts to the top. The maximum fluence also occurs along the $45^{\circ}$ angle behind the pads, as the neutrons experience less moderation and can travel through to the ex-core region more efficiently. The variance in the fluence for Cycles 1 and 2 (Figures 10 and 11) is quite high, even with the CADIS method, and requires more than 1 billion particles to report the fluence with a high degree of accuracy in the outer edges of the concrete bioshield. As a result of the higher variance in the outer edge of the bioshield with 1 billion particles, the concrete bioshield was truncated so that flux in the bioshield beyond $350 \mathrm{~cm}$ with high relative errors are not passed to Grizzly.

A second and slightly smaller peak in the fluence is seen in Figures 10a and 11a in the bioshield liner near the red marker in the figures. The fluence peaks in the steel liner as a result of the increased neutron back scattering between the vessel and the concrete, as well as the neutron capture in Fe experienced in the bioshield liner. Neutrons attenuate again once they penetrate through the bioshield.

The accumulated fluence up to about 43 years is passed off to Grizzly based on a linear extrapolation of the fluence after Cycle 2 calculations. However, it was found that the fluences being calculated by VERA are high $\left(\approx 10^{19} \mathrm{n} / \mathrm{cm}^{2}\right)$. Sensitivity studies on different concrete material and gap sizes between the vessel and bioshield did not explain the elevated fluence values being calculated by VERA. An investigation is currently underway to identify the cause of these discrepancies.

\subsubsection{Neutron Calculations with FW-CADIS}

FW-CADIS calculations through VERA are memory intensive. This differs from the CADIS calculation, because the weight windows that are used to determine whether to split or roulette neutrons are further improved by biasing the adjoint source using a forward deterministic solution. This is done to ideally maintain uniform variance in multiple user tallies or regions of importance in the problem. Neutron transport through the bioshield is a difficult calculation, requiring optimization of the deterministic parameters (such

as the $\mathrm{P}_{\mathrm{n}}$ order) to improve the weight windows. For the work in this report, the default $\mathrm{P}_{0}$ order was used to perform the FW-CADIS calculation. 


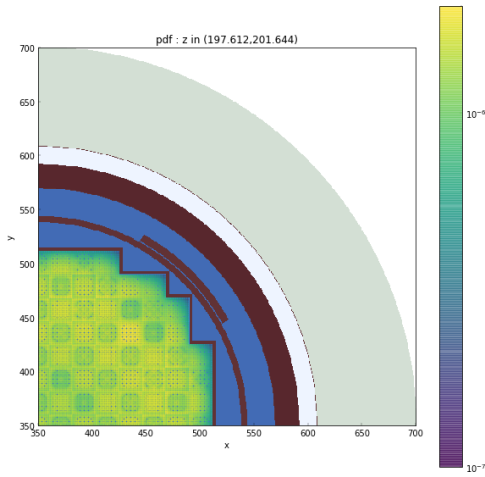

(a) ${ }^{235} \mathrm{U}$ at $\mathrm{BOC}$

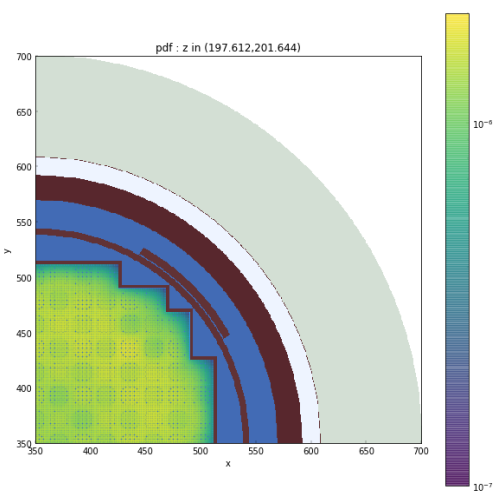

(c) ${ }^{238} \mathrm{U}$ at $\mathrm{BOC}$

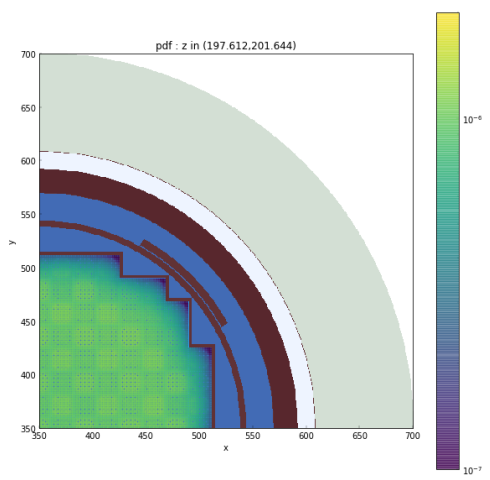

(e) ${ }^{239}$ Pu at EOC

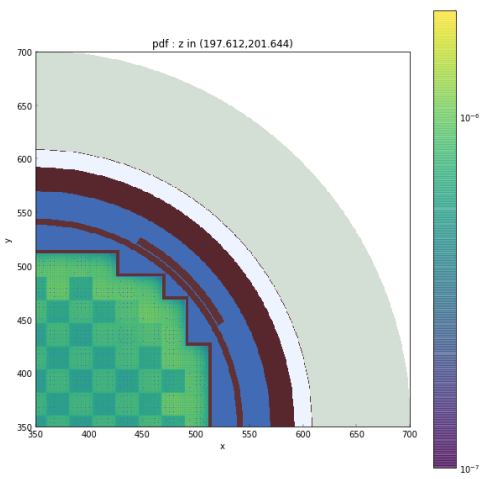

(b) ${ }^{235} \mathrm{U}$ at EOC

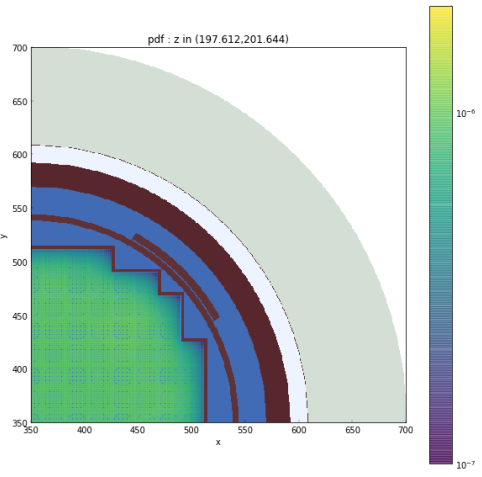

(d) ${ }^{238} \mathrm{U}$ at EOC

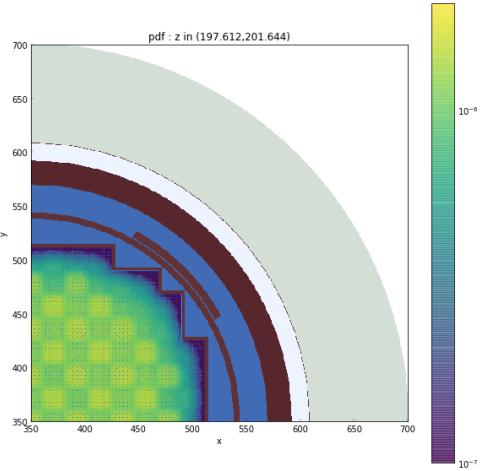

(f) ${ }^{241} \mathrm{Pu}$ at EOC

Figure 5. Fission source strength as a PDF at BOC and EOC passed from MPACT to Shift for WBN1 Cycle 1. [Note: $\mathrm{x}$-axis in $\mathrm{cm}$ and $\mathrm{y}$-axis in $\mathrm{cm}$ ]. 


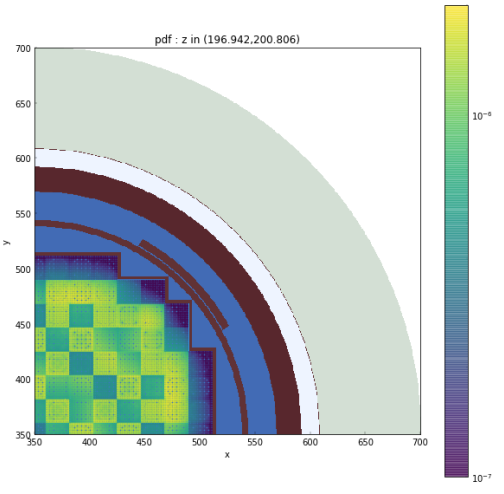

(a) ${ }^{235} \mathrm{U}$ at BOC

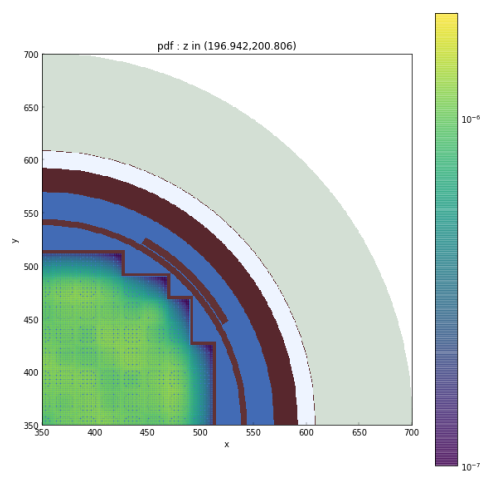

(c) ${ }^{238} \mathrm{U}$ at BOC

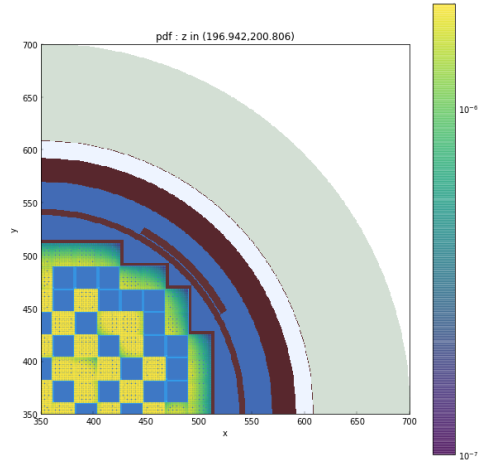

(e) ${ }^{239} \mathrm{Pu}$ at BOC

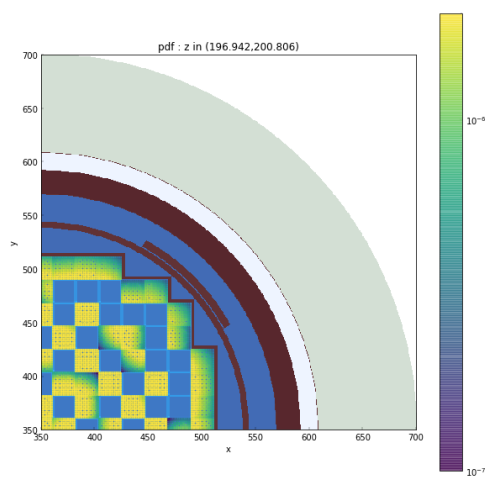

(g) ${ }^{241} \mathrm{Pu}$ at BOC

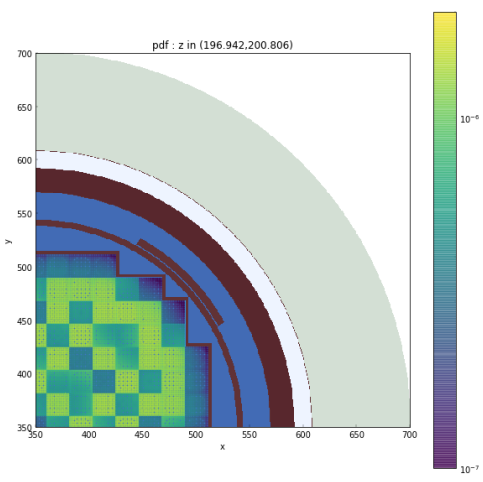

(b) ${ }^{235} \mathrm{U}$ at EOC

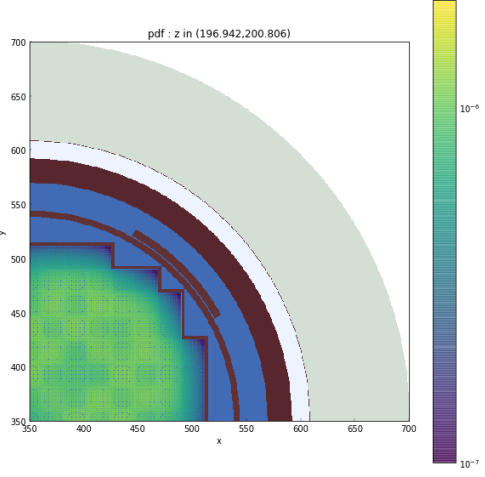

(d) ${ }^{238} \mathrm{U}$ at EOC

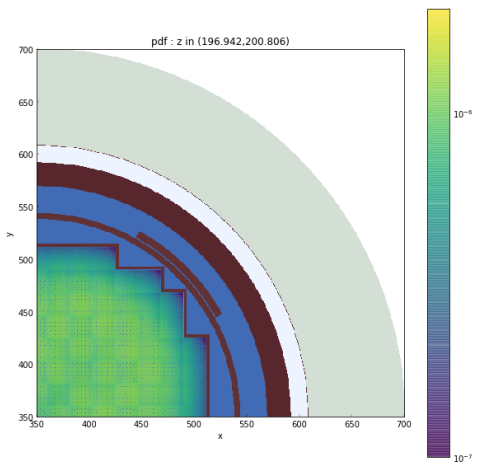

(f) ${ }^{239}$ Pu at EOC

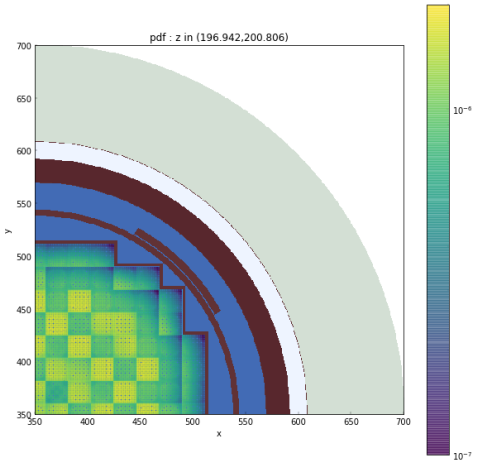

(h) ${ }^{241}$ Pu at EOC

Figure 6. Fission source strength as a PDF at BOC and EOC passed from MPACT to Shift for WBN1 Cycle 2. [Note: $\mathrm{x}$-axis in $\mathrm{cm}$ and $\mathrm{y}$-axis in $\mathrm{cm}$ ]. 


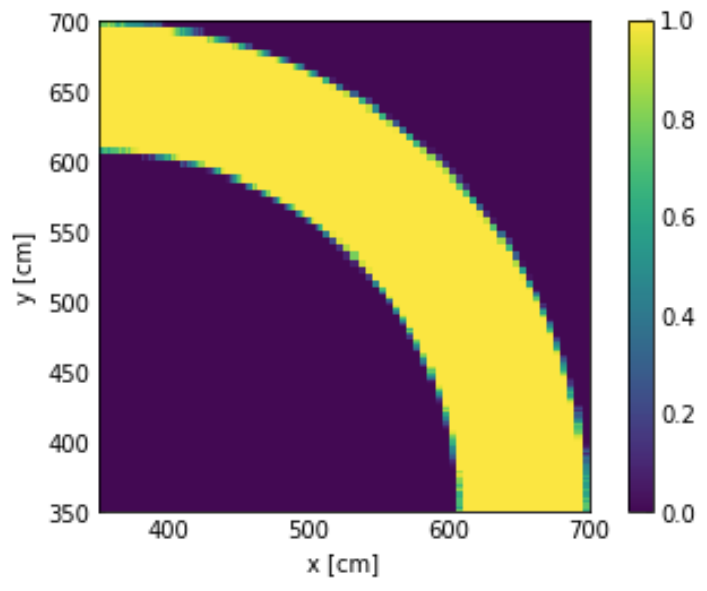

Figure 7. Adjoint source showing the region of importance to this problem which extends from the RPV liner to the bioshield (yellow shows the most important region, and blue is the least important). [Note: $\mathrm{x}$-axis in $\mathrm{cm}$ and $\mathrm{y}$-axis in $\mathrm{cm}$ ].

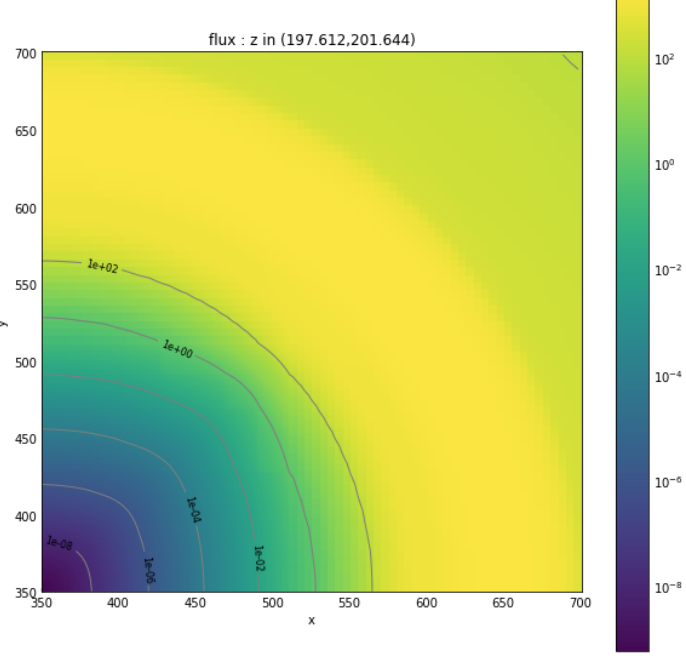

Figure 8. Total adjoint flux showing the importance to the region of interest which extends from the RPV liner to the bioshield (yellow shows the most important region, and blue is the least important).

[Note: $\mathrm{x}$-axis in $\mathrm{cm}$ and $\mathrm{y}$-axis in $\mathrm{cm}$ ]. 


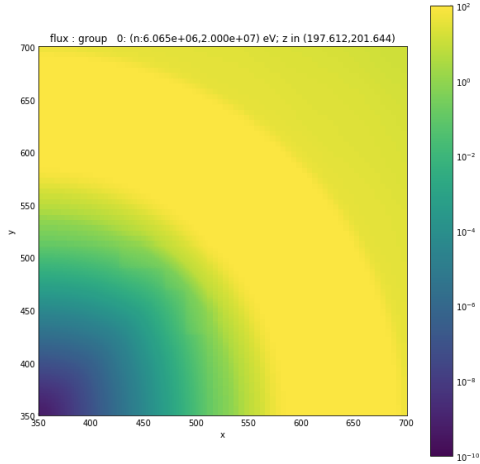

(a) $6.065<\mathrm{E}<20 \mathrm{MeV}$

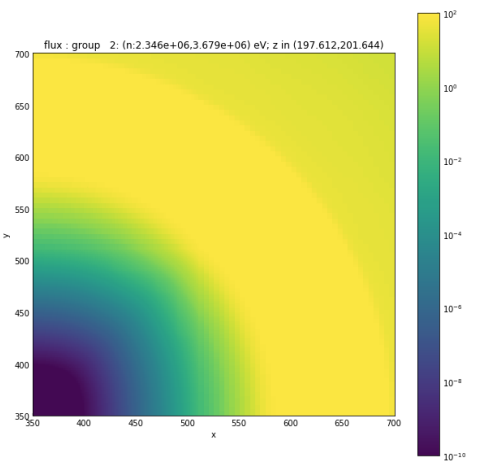

(c) $2.346<\mathrm{E}<3.679 \mathrm{MeV}$

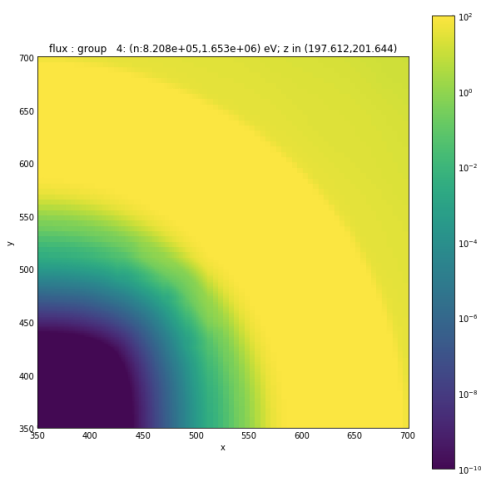

(e) $0.8208<\mathrm{E}<1.653 \mathrm{MeV}$

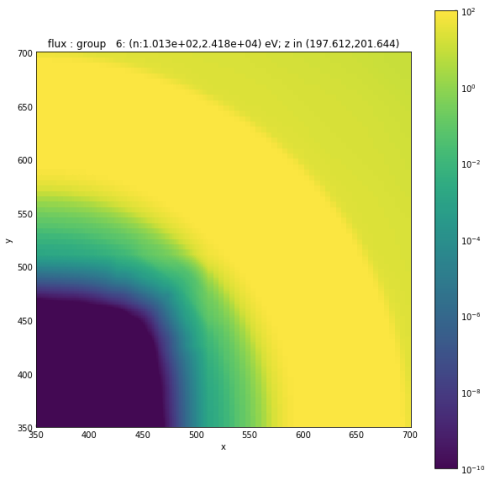

(g) $0.1013<$ E $<24.18 \mathrm{keV}$

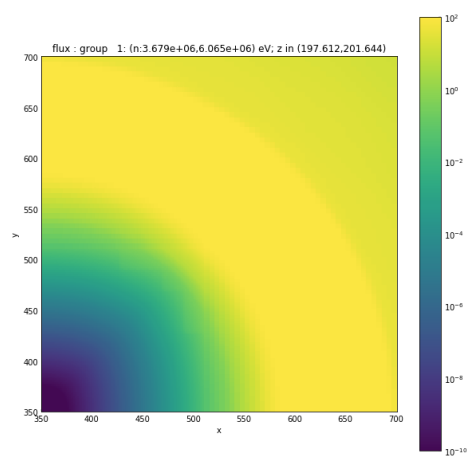

(b) $3.679<$ E $<6.065 \mathrm{MeV}$

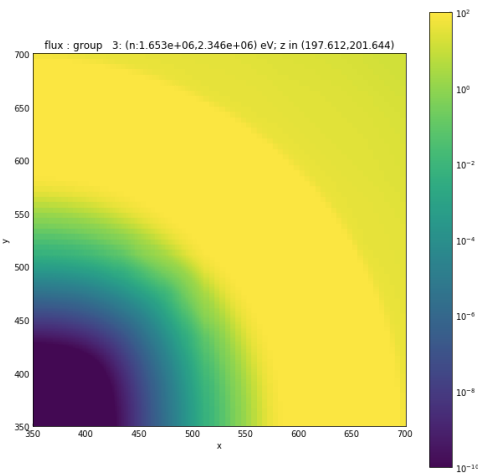

(d) $1.653<$ E $<2.346 \mathrm{MeV}$

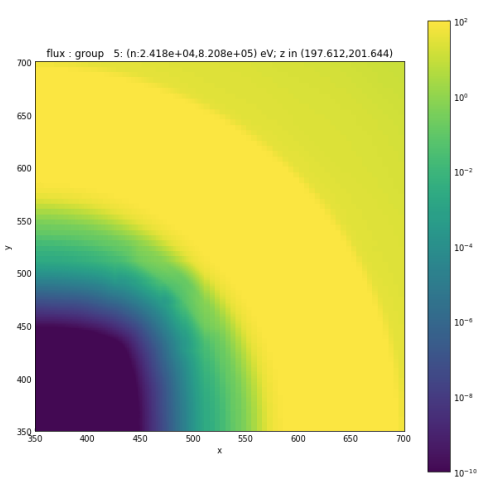

(f) $24.18<$ E $<820.8 \mathrm{keV}$

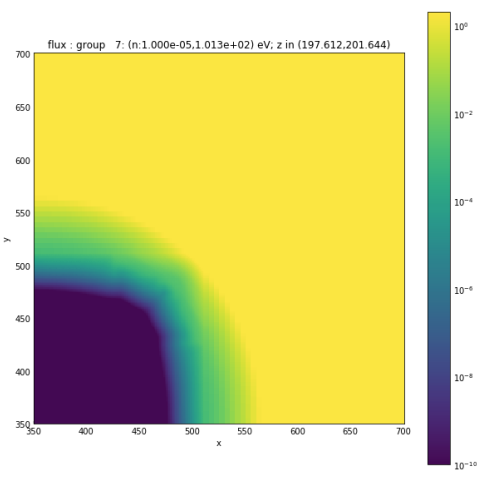

(h) $1 \mathrm{e}-5<\mathrm{E}<101.3 \mathrm{eV}$

Figure 9. Groupwise adjoint flux generated using CADIS showing the importance of particles to the region of interest for Cycle 1. [Note: $\mathrm{x}$-axis in $\mathrm{cm}$ and $\mathrm{y}$-axis in $\mathrm{cm}$ and all plots are on the same color scqle.] 


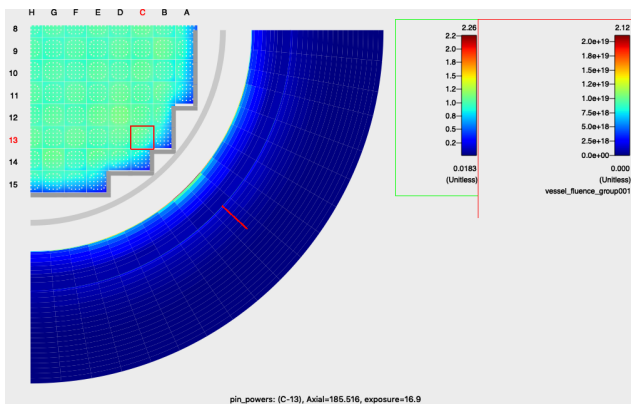

(a) Radial fluence at $\mathrm{z}=188 \mathrm{~cm}$

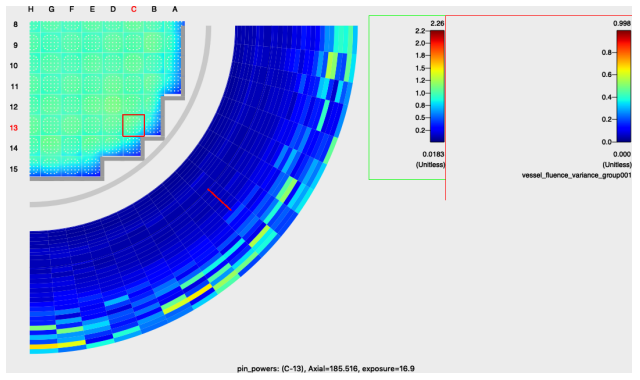

(c) Variance in radial fluence at $\mathrm{z}=188 \mathrm{~cm}$

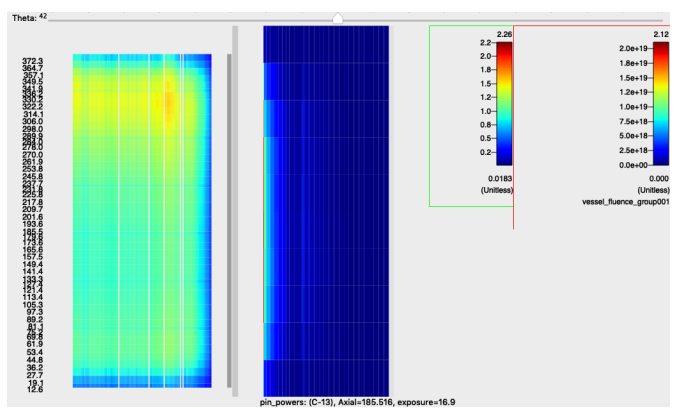

(b) Axial fluence at $\theta=45^{\circ}$

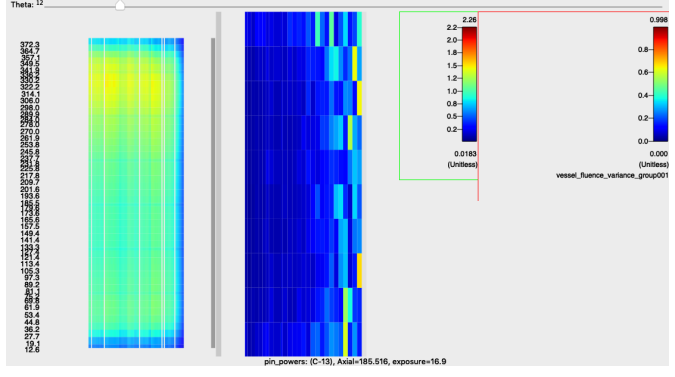

(d) Variance in axial fluence at $\theta=45^{\circ}$

Figure 10. WBN1 Cycle 1 vessel fluence and variance as seen in VERAView.

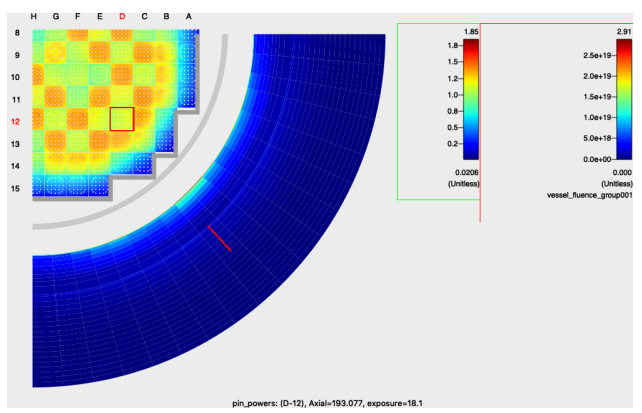

(a) Radial fluence at $\mathrm{z}=193 \mathrm{~cm}$

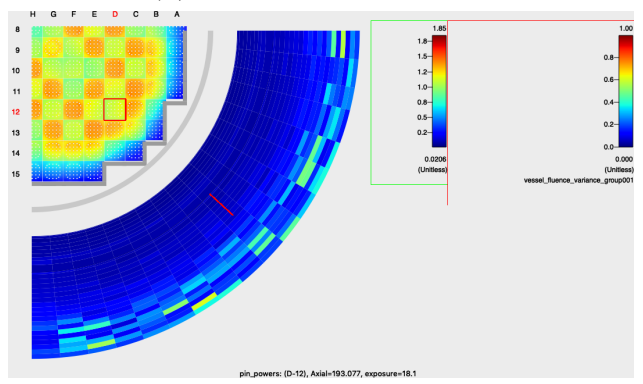

(c) Variance in radial fluence at $\mathrm{z}=188 \mathrm{~cm}$

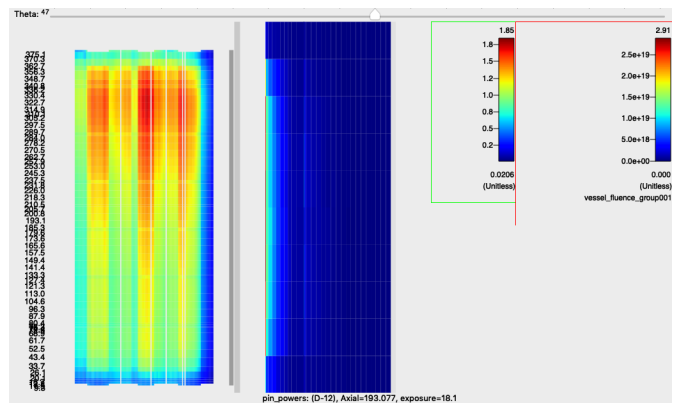

(b) Axial fluence at $\theta=45^{\circ}$

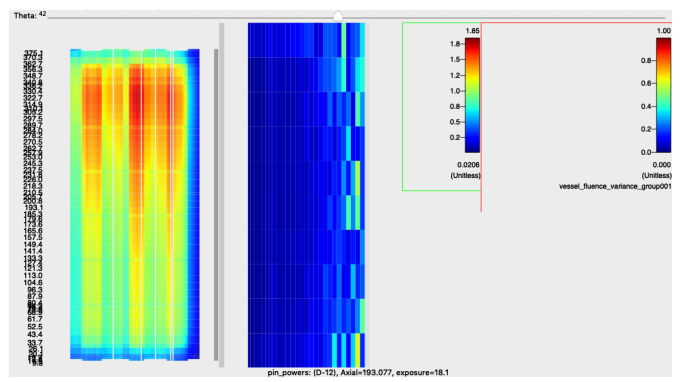

(d) Variance in axial fluence at $\theta=45^{\circ}$

Figure 11. WBN1 Cycle 2 vessel fluence and variance as seen in VERAView. 
Since these FW-CADIS calculations are more memory intensive than the CADIS calculations in VERA, the WBN1 calculations for Cycles 1 and 2 could not be successfully completed. The FW-CADIS calculation for Cycle 1 was terminated after 6 of the 32 depletion steps were completed, and the Cycle 2 calculation was terminated after 5 of the 22 depletion steps. Further investigation into this matter should be conducted to resolve these memory issues. Note that the bioshield for these problems extends further out to 518.16 $\mathrm{cm}$ instead of the $350 \mathrm{~cm}$ radius for the cases that were run with CADIS (this would increase memory requirements).

In light of the memory issues, Cycles 1 and 2 inputs were modified with the bioshield extending out to 350 $\mathrm{cm}$, as was in the previous case, and they were run with only one statepoint. While the MPACT and Shift calculations for these cases ran successfully, the transfer of data from Shift to MPACT did not complete and the calculation was terminated after it hit the walltime limit set by the user. Although this final transfer between Shift and MPACT did not take place, the Shift calculation generates a Shift output file which contains all the flux tally data. The relative errors in the flux plots (generated with CADIS and FW-CADIS methods) in the RPV and bioshield after the first statepoint are shown in Figures 12 and 13. While it appears that a total of 1 billion particles is not adequate to produce results with good statistics deeper into the concrete shield with either CADIS or FW-CADIS methods and the default parameters in VERA, it must be noted that the statistical errors do appear to be somewhat more uniform in the results generated with FWCADIS. This is slightly more apparent when viewing the axial profile in Figure 13. Figure 14 shows that the entire problem is important for transporting neutrons to the region of interest, so the particles need to be transported everywhere. The adjoint flux generated with FW-CADIS tries to uniformly reduce the statistical error. As a result, the variance reduction seen by running FW-CADIS as opposed to CADIS is subtle. When optimizing for a single response, in this case the outer ring of the bioshield, no performance improvements can be expected from FW-CADIS over CADIS. However, if the bioshield flux in the fast energy range can be optimized over a mesh tally in the bioshield, then the FW-CADIS method is expected to show performance improvements over CADIS. Currently, it is not possible to optimize for a mesh tally or for flux in a specific energy range using Shift. This feature could be considered for future work.

A parametric study was performed by approximately doubling the mesh size in the radial direction within the vessel and shield and was run for only WBN1 Cycle 2 with FW-CADIS (Figure 15). The increase in mesh size reduced the statistical errors as expected because the likelihood of a particle passing through a tally and thus scoring within the tally is higher.

Next, the $P_{n}$ order for scattering was changed from the default $P_{0}$ to $P_{1}$. The previous case with the larger mesh tally was run to determine whether the change in scattering order would improve the results with FWCADIS. The results in Figure 16 indicate that going up to $\mathrm{P}_{1}$ scattering order does not necessarily improve the results. When closely inspecting the groupwise adjoint flux for this case, the Group 6 adjoint flux for neutron energies ranging from 0.1013 to $24.18 \mathrm{keV}$ has negative values in the core region, producing a blank white spot in the logarithmic plot (see Figure 17). This indicates that the Denovo mesh in the core region requires further optimization to yield results with better statistical performance when using $\mathrm{P}_{1}$ scattering. Subsequently, the results seen with higher order scattering moments in the deterministic calculation do not yield better performance with the default grid parameters. Although there are negative adjoint fluxes being produced in this case, they are treated such that they will not bias the final solution.

Finally, the original Cycle 2 input with the fine mesh tally in the vessel and bioshield with FW-CADIS was run with 4 billion particles. The results in Figure 18 show that when running a sufficiently high number of particle histories, a reduction in the relative errors in the tally fluxes is seen because the chances of scoring 


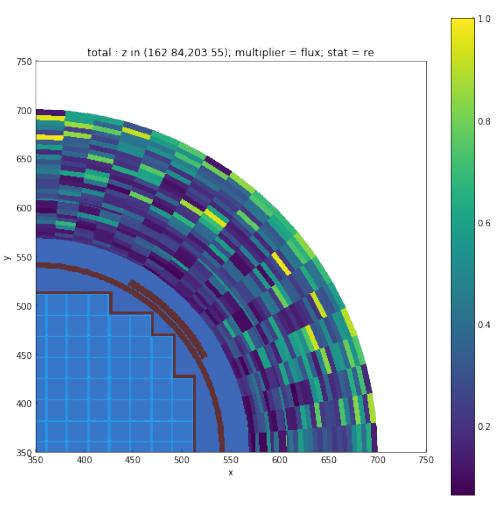

(a) Relative error in Cycle 1 with CADIS

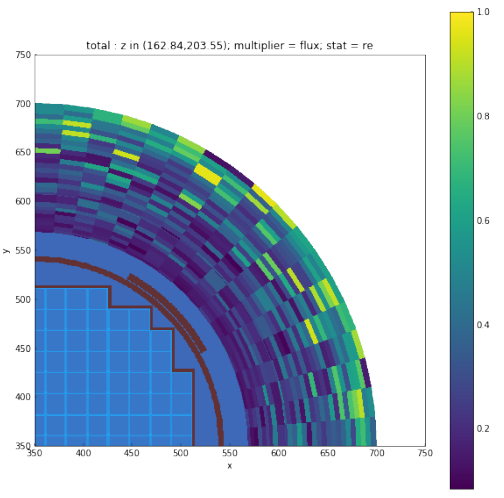

(c) Relative error in Cycle 2 with CADIS

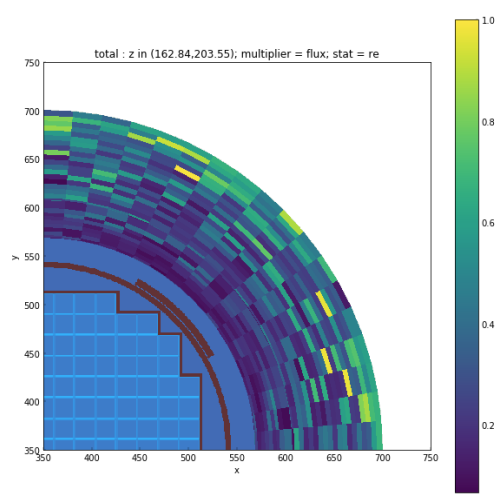

(b) Relative error in Cycle 1 with FWCADIS

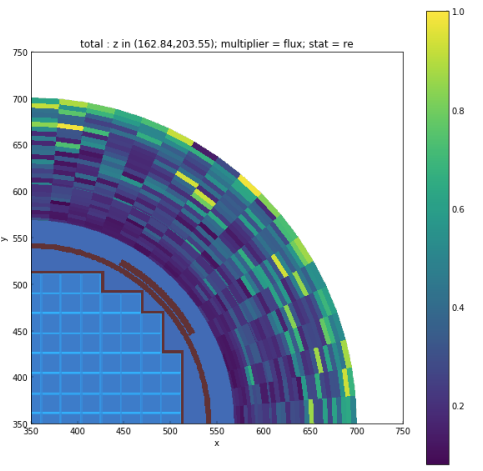

(d) Relative error in Cycle 2 with FWCADIS

Figure 12. Relative error in the flux in the $z$ mesh extending from 162.84 to $203.55 \mathrm{~cm}$ for WBN1 Cycles 1 and 2 at the first statepoint. [Note: $x$-axis in $\mathrm{cm}$ and $y$-axis in $\mathrm{cm}$ ].

within the tally increase. As demonstrated by the studies performed for this report, running cases with more particle histories and a larger mesh tally (about $10 \mathrm{~cm}$ in the radial direction instead of about $5 \mathrm{~cm}$ ) will yield lower statistical errors.

\subsection{Computing Resources and Feedback on Code Performance}

All the calculations were performed on INL's Sawtooth computing cluster using VERA 4.3RC5. There are 48 cores per node on Sawtooth. However, the Watts Bar Cycles 1 and 2 VERA inputs were run on 24 and 16 cores per node, respectively, while utilizing the memory on the entire node for both CADIS and FW-CADIS calculations. Each node has approximately 190 GB of memory.

The WBN1 Cycle 1 CADIS calculation with 32 statepoints completed in 33.4 hours (see Table 1). For this calculation, Shift and MPACT ran on two threads per MPI task, with Shift running on 400 cores, and MPACT running on 896 cores. However, the memory on 54 nodes (2,592 cores) was used to perform this calculation. Each Shift calculation took an average of 30 minutes to complete, with a maximum time of 37.6 minutes, and a minimum time of 24.5 minutes. The average MPACT calculation took about 1 hour. The 


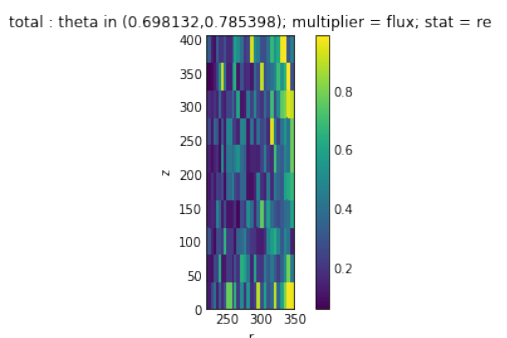

(a) Relative error in Cycle 1 with CADIS

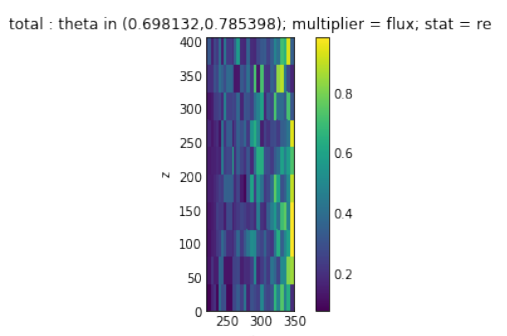

(c) Relative error in Cycle 2 with CADIS

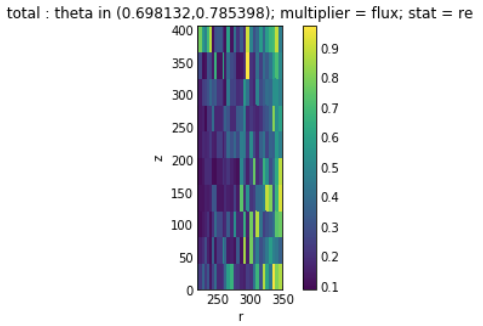

(b) Relative error in Cycle 1 with FWCADIS

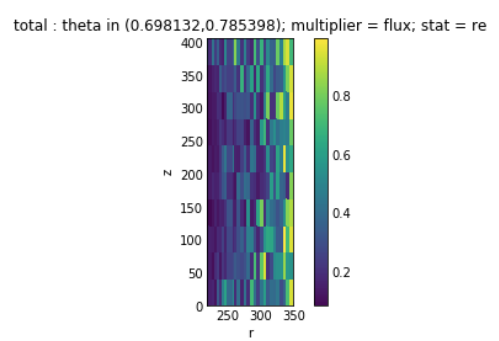

(d) Relative error in Cycle 2 with FWCADIS

Figure 13. Relative error in the flux in the $\theta$ mesh extending from 0.698 to 0.785 radians for WBN1 Cycles 1 and 2 at the first statepoint.

longest MPACT statepoint calculation took 2.8 hours, and the shortest MPACT statepoint calculation took 23 minutes.

The WBN1 Cycle 2 CADIS calculation with 22 statepoints completed in 18 hours and 11 minutes (see Table 2). For this calculation, Shift and MPACT also ran on two threads per MPI task, with Shift running on 400 cores and MPACT running on 1,560 cores. The memory on 123 nodes (5,904 cores) was used for this calculation. Each Shift calculation took about 37 minutes to complete, with a maximum time of 46 minutes and a minimum statepoint calculation time of 30 minutes. The average MPACT statepoint calculation took about 45 minutes to complete. The longest MPACT statepoint calculation took about 1 hour and 18 minutes, and the shortest MPACT statepoint calculation took about 32.5 minutes to complete.

The WBN1 Cycle 1 CADIS calculation was completed using the VERA OpenMPI build on Sawtooth, and the Cycle 2 CADIS calculation ran to completion with the MVAPICH build. Calculations performed with the MVAPICH build were more stable than the OpenMPI build, where there were fewer chances of MPI errors being produced.

All the FW-CADIS calculations were performed with the MVAPICH build. Even though this build is considered more stable, the memory issues prevented the calculation from running to completion, so timing studies are not shown here for the FW-CADIS calculations. As a result, the parametric studies with varying mesh sizes and particle histories were performed at only one statepoint. During these single statepoint calculations, it was noted that the transfer from Shift to MPACT did not complete successfully after the successful Shift calculation. Although a multi-statepoint calculation does not yield this issue, it is unclear why a single statepoint calculation would behave differently. This issue is noted here for further investigation. 
flux : group 0: (n:6.065e+06,2.000e+07) eV; $z$ in $(197.612,201.64$ flux : group 1: (n:3.679e+06,6.065e+06) eV; $z$ in $(197.612,201.644)$

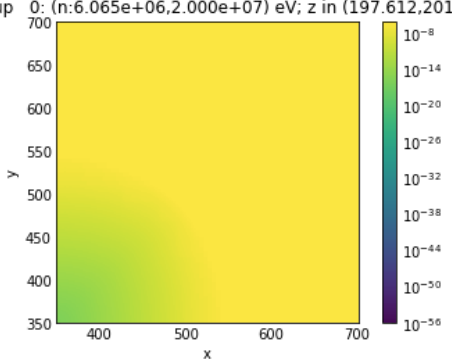

(a) $6.065<\mathrm{E}<20 \mathrm{MeV}$

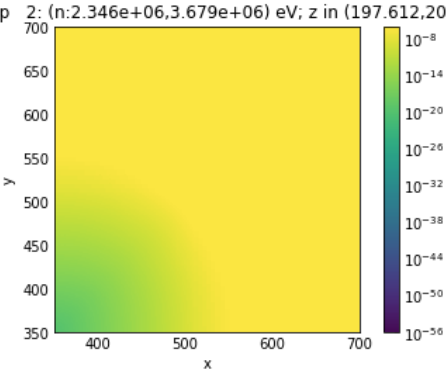

(c) $2.346<\mathrm{E}<3.679 \mathrm{MeV}$

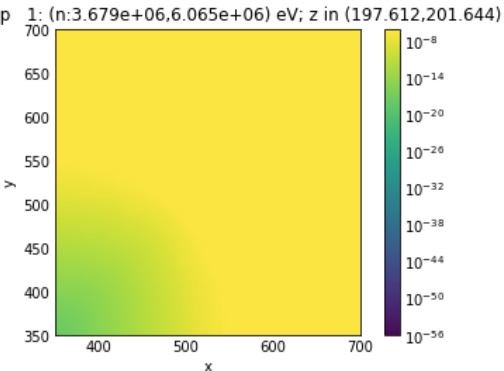

(b) $3.679<\mathrm{E}<6.065 \mathrm{MeV}$

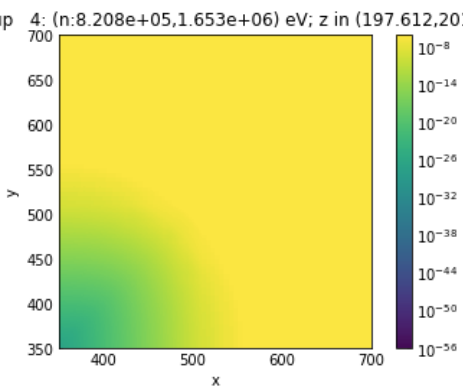

(e) $0.8208<\mathrm{E}<1.653 \mathrm{MeV}$

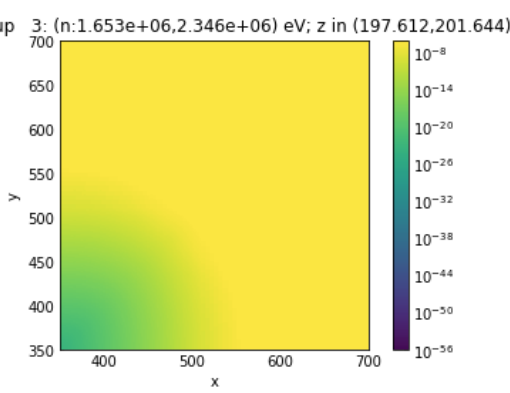

(d) $1.653<\mathrm{E}<2.346 \mathrm{MeV}$

flux : group 4: $(\mathrm{n}: 8.208 \mathrm{e}+05,1.653 \mathrm{e}+06) \mathrm{eV} ; \mathrm{z}$ in $(197.612,201.1$ flux : group $5:(\mathrm{n}: 2.418 \mathrm{e}+04,8.208 \mathrm{e}+05) \mathrm{eV} ; \mathrm{z}$ in $(197.612,201.644)$

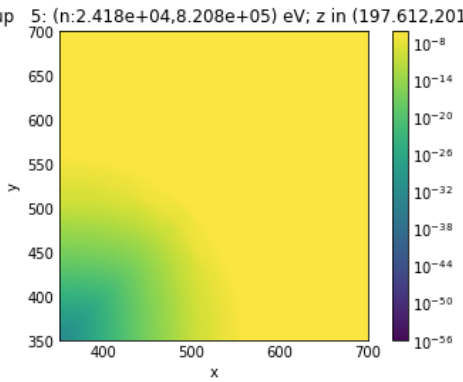

(f) $24.18<\mathrm{E}<820.8 \mathrm{keV}$

flux : group 6: (n:1.013e+02,2.418e+04) eV; $z$ in $(197.612,201.6$ flux : group 7: (n:1.000e-05,1.013e+02) eV; $z$ in $(197.612,201.644)$

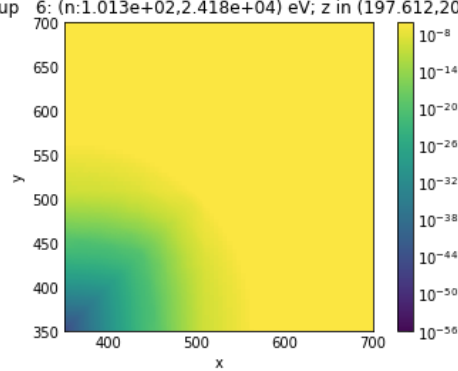

(g) $0.1013<\mathrm{E}<24.18 \mathrm{keV}$

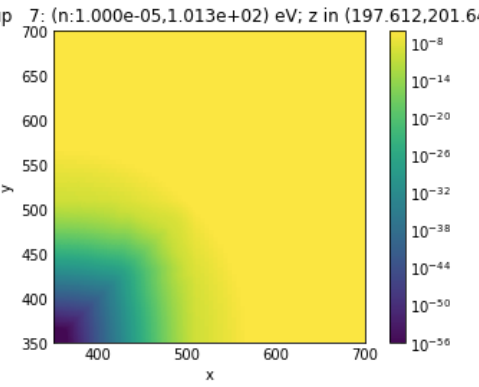

(h) $1 \mathrm{e}-5<\mathrm{E}<101.3 \mathrm{eV}$

Figure 14. Groupwise adjoint flux generated using FW-CADIS that shows the importance of particles to the region of interest for Cycle 1. [Note: $\mathrm{x}$-axis in $\mathrm{cm}$ and $\mathrm{y}$-axis in $\mathrm{cm}$ ]. 


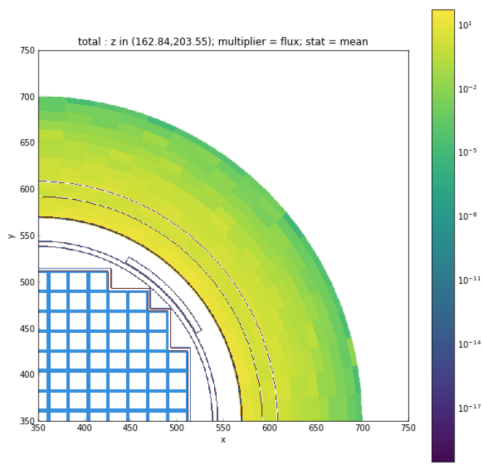

(a) Cycle 2 radial flux with FW-CADIS.

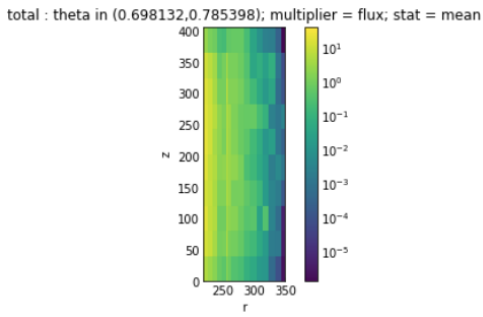

(c) Cycle 2 axial flux with FW-CADIS. (d) Relative error in Cycle 2 axial flux with FW-CADIS.

Figure 15. WBN1 Cycle 2 results for one statepoint with FW-CADIS with a larger mesh tally. Cycle 2 radial flux and relative error in $\mathrm{z}$ direction ranging from 162.84 to $203.55 \mathrm{~cm}$, and axial flux and relative error in the $\theta$ mesh extending from 0.698 radians to 0.785 radians for WBN1 Cycle 2. 


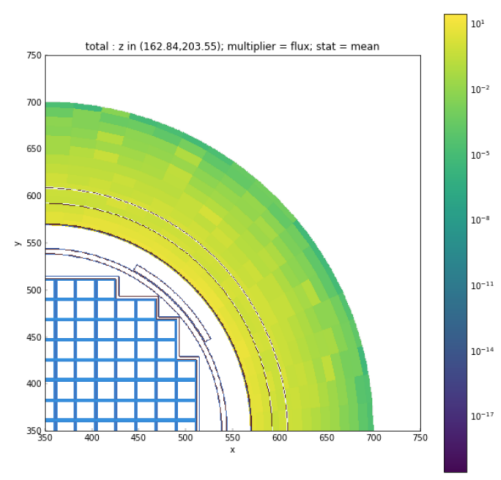

(a) Cycle 2 radial flux with FW-CADIS.

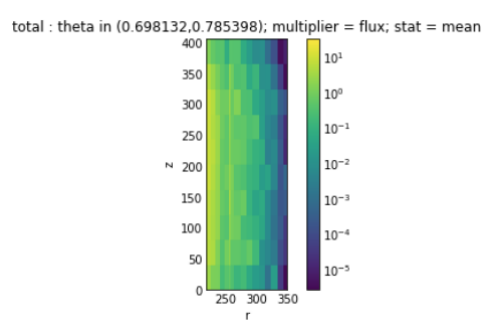

(c) Cycle 2 axial flux with FW-CADIS.

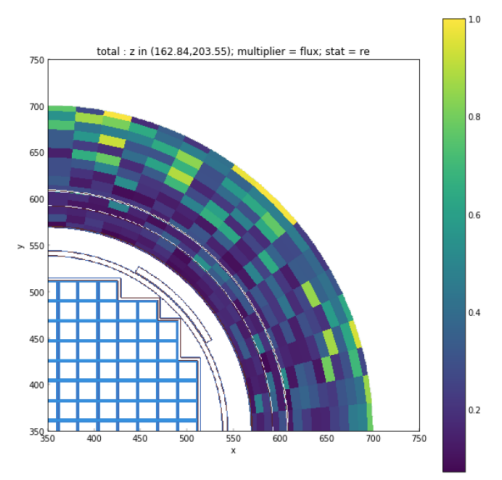

(b) Relative error in Cycle 2 radial flux with FW-CADIS.

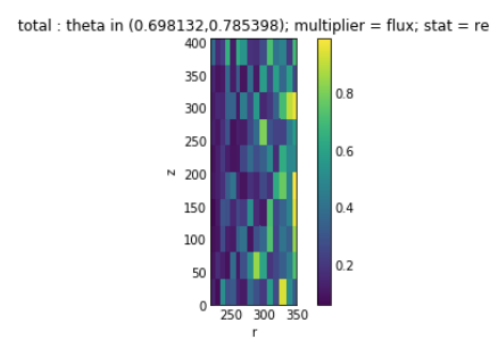

(d) Relative error in Cycle 2 axial flux with FW-CADIS.

Figure 16. WBN1 Cycle 2 results for one statepoint with FW-CADIS and a larger mesh tally and with $P_{1}$ order for scattering in deterministic calculation. Cycle 2 radial flux and relative error in $\mathrm{z}$ direction ranging from 162.84 to $203.55 \mathrm{~cm}$, and axial flux and relative error in the $\theta$ mesh extending from 0.698 to 0.785 radians for WBN1 Cycle 2 .

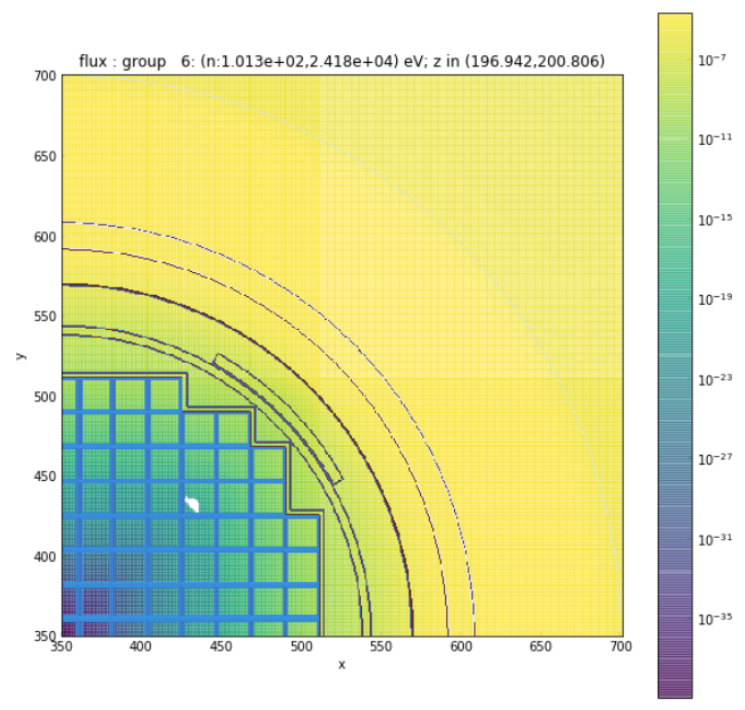

Figure 17. Group 6 adjoint flux $(0.1013<E<24.18 \mathrm{keV})$ for $\mathrm{FW}-\mathrm{CADIS}$ case with $\mathrm{P}_{\mathbf{1}}$ scattering. Note the blank white spot in the core, which indicates the presence of negative adjoint fluxes. 


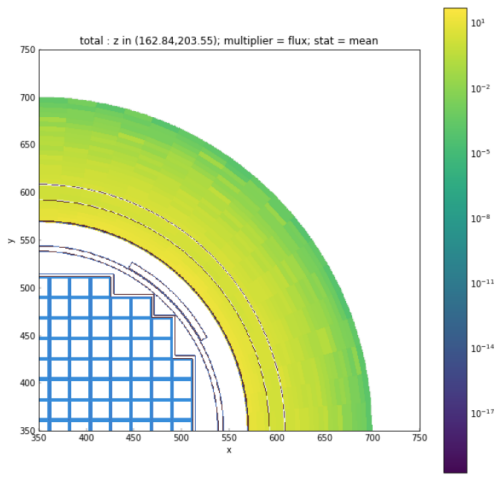

(a) Cycle 2 radial flux with FW-CADIS.

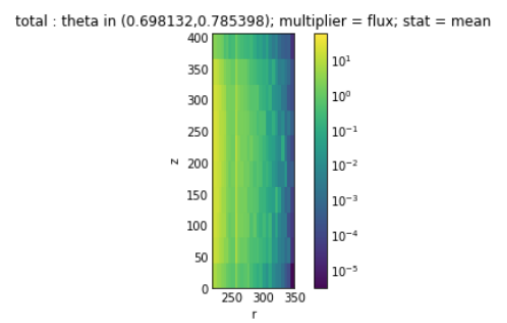

(c) Cycle 2 axial flux with FW-CADIS.

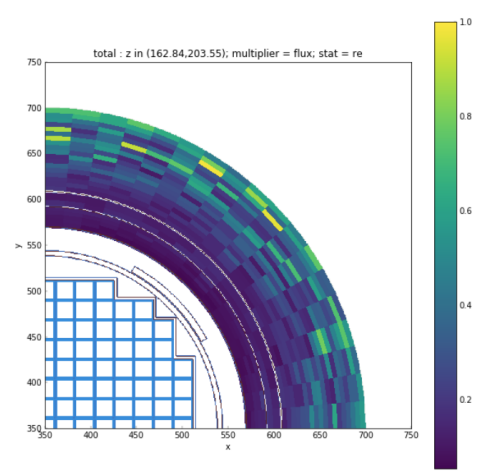

(b) Relative error in Cycle 2 radial flux with FW-CADIS.

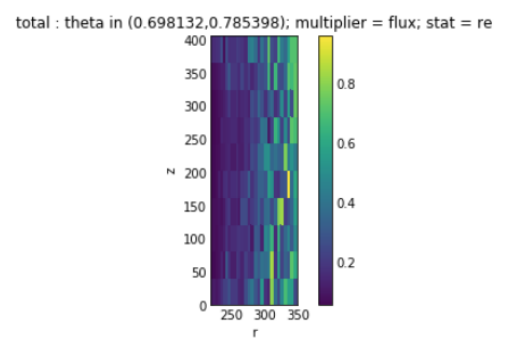

(d) Relative error in Cycle 2 axial flux with FW-CADIS.

Figure 18. WBN1 Cycle 2 results for one statepoint with FW-CADIS and 4 billion particle histories. Cycle 2 radial flux and relative error in z direction ranging from 162.84 to $203.55 \mathrm{~cm}$, and axial flux and relative error in the $\theta$ mesh extending from 0.698 to 0.785 radians for WBN1 Cycle 2. 
Finally, it is briefly noted here that further testing was performed with neutron-photon (np) coupled calculations with Shift in VERA for WBN1 Cycle 1. The results are not shown here because the run times were slow. The np-coupled calculations were run with 100 million particles per statepoint, and after 96 hours of walltime, only 10 statepoints had finished running. Therefore, there is room for significant optimization for these types of calculations in VERA. It is important to perform np-coupled calculations for gamma heating assessments on the vessel and bioshield, which are important for aging and lifetime extension studies. 
Table 1. Cycle 1 run times in minutes.

\begin{tabular}{|c|c|c|}
\hline Statepoint & MPACT & Shift \\
\hline 1 & 23.4 & 24.5 \\
\hline 2 & 61.7 & 24.8 \\
\hline 3 & 60.4 & 25.7 \\
\hline 4 & 46.5 & 26.1 \\
\hline 5 & 36.8 & 26.2 \\
\hline 6 & 37.5 & 26.2 \\
\hline 7 & 38.2 & 26.5 \\
\hline 8 & 32.9 & 26.7 \\
\hline 9 & 46.6 & 26.9 \\
\hline 10 & 29.7 & 27.1 \\
\hline 11 & 30.9 & 27.2 \\
\hline 12 & 66.9 & 27.6 \\
\hline 13 & 50.1 & 28.1 \\
\hline 14 & 34.6 & 28.4 \\
\hline 15 & 79.8 & 28.4 \\
\hline 16 & 89.0 & 28.9 \\
\hline 17 & 40.5 & 29.4 \\
\hline 18 & 49.4 & 29.6 \\
\hline 19 & 60.1 & 30.1 \\
\hline 20 & 134.2 & 30.7 \\
\hline 21 & 45.2 & 30.8 \\
\hline 22 & 52.5 & 31.8 \\
\hline 23 & 43.1 & 32.5 \\
\hline 24 & 85.4 & 33.7 \\
\hline 25 & 73.3 & 34.9 \\
\hline 26 & 35.3 & 34.6 \\
\hline 27 & 70.1 & 35.6 \\
\hline 28 & 35.7 & 36.3 \\
\hline 29 & 140.3 & 37.1 \\
\hline 30 & 101.8 & 37.0 \\
\hline 31 & 104.6 & 37.6 \\
\hline 32 & 166.5 & 37.5 \\
\hline Average & 62.6 & 30.3 \\
\hline
\end{tabular}

Table 2. Cycle 2 run times in minutes.

\begin{tabular}{ccc}
\hline Statepoint & MPACT & Shift \\
\hline 1 & 48.6 & 30.3 \\
2 & 60.3 & 32.2 \\
3 & 34.0 & 30.7 \\
4 & 32.5 & 33.1 \\
5 & 60.3 & 33.8 \\
6 & 44.8 & 31.9 \\
7 & 41.9 & 32.1 \\
8 & 59.1 & 31.8 \\
9 & 36.7 & 33.4 \\
10 & 39.1 & 33.8 \\
11 & 35.5 & 34.0 \\
12 & 35.7 & 35.5 \\
13 & 43.2 & 35.4 \\
14 & 59.8 & 36.4 \\
15 & 38.1 & 38.5 \\
16 & 40.3 & 39.0 \\
17 & 40.8 & 41.3 \\
18 & 45.2 & 41.9 \\
19 & 43.6 & 44.6 \\
20 & 60.0 & 45.9 \\
21 & 48.6 & 46.3 \\
22 & 40.9 & 43.0 \\
Average & 45.0 & 36.6 \\
\hline
\end{tabular}

Note: These runs were completed on Sawtooth, with Shift running on 400 cores and MPACT on 1560 cores while using the memory on 5,904 cores.

Note: These runs were completed on Sawtooth, with Shift running on 400 cores and MPACT on 896 cores while using the memory on 2,592 cores. 


\section{GRIZZLY CALCULATIONS}

\subsection{Literature review}

Note: This section includes verbatim text from a journal paper authored by Le Pape [2015], provided here for the sake of completeness of the literature review until 2015.

Limited literature is available on the structural significance of irradiation for concrete primarily because irradiated concrete has been mostly studied with the perspective of material design and qualification. Nevertheless, a few structural models for concrete containment and internal structures [Mirhosseini, 2010, Mirhosseini et al., 2014] and for shield structures [Pomaro et al., 2011, Salomoni et al., 2014, Andreev and Kapliy, 2014, Le Pape, 2015, Giorla et al., 2016, Bruck et al., 2019, Kambayashi et al., 2020] were recently published.

Mirhosseini et al. have developed a reinforced concrete $(R C)$ membrane model accounting for the concrete strength reduction resulting from the irradiation. The finite element model uses the modified compression-field theory developed by Vecchio and Collins [1982, 1986] from an extensive set of structural experiments on RC panels subjected to varied combined compression and shear in-plane loading. The behavior of RC membrane elements, viewed as scale models for RC walls and shells in nuclear power plants (NPPs), under shear, and combination of shear and tension and compression is analyzed in terms of strength (in-plane loading), ductility and failure mode. The concrete compressive and tensile strength reduction is based on a direct interpretation of Hilsdorf et al.'s curves including, in particular, Dubrovskii et al.'s debatable data [Dubrovskii et al., 1966, Fujiwara et al., 2009] at very high fluences $\left(>10^{+21} \mathrm{n. \textrm {cm } ^ { - 2 }}\right)$. Possible irradiation effect on carbon steel reinforcement is not accounted for. This assumption can be justified only for fluence below $1.0 \times 10^{+20} \mathrm{n} . \mathrm{cm}^{-2}$ based on Janowiak et al. [reapproved 2010] report: "Neutron irradiation produces changes in the mechanical properties of carbon steel (increase in yield stress and rise in the ductile-brittle transition temperature). As a consequence, steel reinforcement exposed to high cumulative neutron fluence (above $1.0 \times 10^{+20}$ $n . \mathrm{cm}^{-2}$ ) can experience reduced ductility." The interest of Mirhosseini et al.' approach is to conduct structural failure analysis of NPPs' $R C$ components using a nonlinear finite element tool. However, the use of membrane elements for modeling irradiated-CBS (or RPVSSS) is particularly debatable because of the actual thickness to height ratio of such component and because of the presence of radiation fields profile [Remec et al., 2014] through the member thickness. Modeling nonuniform thermo-hygro-radiological effects in the CBS requires either the use of multilayers shell elements or $3 D$-volume elements, or $2 D$-surface element $r$ - $z$ in a cylindrical model, or 1D-r segment element in a radial-cylindrical model. Finally, although Mirhosseini et al. acknowledge that "Deterioration of shielding concrete is mostly due to volume changes of concrete. Aggregate expansion is the main factor of radiation deterioration in concrete in NPPs", the possibility RIVE-induced stresses is surprisingly not accounted for, in their modeling work.

The approach followed by Pomaro et al. [2011], Salomoni et al. [2014] is developed on the basis of an existing coupled nonlinear thermo-hygro mechanical $(\mathrm{TH} \rightarrow \mathrm{M})$ model initially developed by Schrefler et al. [1989], Baggio et al. [1995], Majorana et al. [1998]. Heat transfer and moisture transport are coupled following a scheme developed by Schrefler et al. [1989], 
derived from the pioneer work of Luikov [1975]. Radiation effects are assumed uncoupled from thermal and moisture transport. The concrete mechanical model is fairly extensive: It includes thermal expansion, autogenous shrinkage, creep, load-induced thermal strain rate, damage and plasticity effects. The incremental isotropic damage formulation follows Mazars and PijaudierCabot [1989]'s theory combining tensile and compression strain effects on damage. Equivalent damage index is assumed to result from a cumulative (multiplicative effect in the sense of Gérard et al. [1998], Nechnech et al. [2002] ) effect of mechanical, thermo-chemical and radiation damage: $\tilde{D}=1-\left(1-D_{m}\right)\left(1-D_{T}\right)\left(1-D_{r}\right)$, where $\tilde{D}, D_{m}, D_{T}$ and $D_{r}$ are respectively the overall, mechanical, thermal and irradiation-induced damage. Concrete radiation damage is determined assuming a lower bound exponential fit of Hilsdorf et al.'s data showing a gradual decrease of the elastic modulus to, what is interpreted as an asymptotic value of $50 \%$ of the initial elastic modulus with increased neutron fluence. The " $1 D$ " simulation of a biological shield is performed on a 3.5 meter $(\approx 11.5 \mathrm{ft}$.) thick prism to obtain damage profile within the thickness of the concrete shield. The model simulations predict that the irradiation effects are the only source of damage in the concrete shield and that damage progresses inward the shield with the accumulated fluence. The calculated stress levels are particularly low (below $1 \mathrm{MPa}$ ) even in the presence of radiation. The maximum estimated damage after 50 years of operation is equal to the threshold chosen by the author for radiation damage in concrete (i.e., $\approx 0.5$ ). The maximum damage is observed at the surface of the CBS, i.e., where the fluence reaches its peak value. For the ordinary concrete, the damage profiles appear to decrease almost linearly from the surface with an approximate gradient of $\approx-0.8 \mathrm{~m}^{-1}$ depth for fast neutrons and $\approx-1.2 \mathrm{~m}^{-1}$ depth for thermal neutrons. After sufficient irradiation exposure time, the damage profile exhibits a plateau caused by damage saturation resulting from the interpretation of Hilsdorf et al.'s "elastic modulus vs. neutron' fluence" plot. Depending on the energy level used for the interpretation of Hilsdorf et al.'s data, the maximum damage depth, defined by $D>0$, after 50 years of operation is estimated around 1.0 meter and 0.7 meter, respectively for fast neutrons and thermal neutrons. These rather deep damage penetration are the result of the very high total fluence exposure assumed $-10^{+12} n \cdot \mathrm{cm}^{-2} \mathrm{~s}^{-1}$-which leads to a total fluence of about $1.6 \times 10^{+21} n . \mathrm{cm}^{-2}$ after 50 years of operation. Such a flux is one to two orders of magnitude higher than the estimated bounding value for PWR CBS [Esselman and Bruck, 2013, Remec et al., 2014]. Pomaro et al.'s approach contains many important features for modeling the effects of coupled $T-H \rightarrow M$ effects on irradiated concrete. Interestingly though, the effects of moisture transport and temperature on the cumulated damage appears to be negligible because of the low temperature and small induced-stress found in Pomaro et al.'s simulation. It is striking however that the proposed model ignores the potential effects of RIVE which can potentially develop large stresses, and subsequently, mechanical damage. This would lead to confirm that, if any significant damage is to be created, radiation damage and RIVE would be its main causes.

Andreev and Kapliy [2014] were the first to develop an 1D-cylindrical model accounting for the radiation-induced deformation and, the loss of elastic modulus induced by temperature and irradiation. However, the fluence (up to $5 \times 10^{+24} \mathrm{n} . \mathrm{cm}^{-2}$, the temperature $\left(500{ }^{\circ} \mathrm{C}\right.$ ) and the geometry (inner radius at 3.3 meter) are not representative of LWR conditions Large circumferential compressions are calculated in the region close to the inner radius while important circumferential tensile stresses are obtained toward the back of the CBS. 
Subsequently, Le Pape [2015] improved Andreev and Kapliy's 1D-model of a prototypical unreinforced CBS at the elevation of the belt line by introducing irradiated concrete's mechanical properties based on the data collected in Field et al. [2015]. Young's modulus, the tensile strength, and the compressive strength are functions of the fluence exposure. Degradation occurs for fluence levels higher than $10^{19} \mathrm{n} \cdot \mathrm{cm}^{-2}$. The model does not include mechanical damage in the sense of Mazars et al. [2015]. The simulations confirm Andreev and Kapliy's conclusions: for long-term fluence exposure in PWRs, the portion of the CBS located in the vicinity of the reactor cavity is subject to high compressive stresses caused by differential RIVEs. Those biaxial compressive stresses in the vertical and circumferential directions largely exceed the residual irradiated compressive strength, while important deformation occurs in the radial direction. This stress state is analogous to submitting a thick cylinder to a thermal shock by increasing the temperature in the cavity. The amplitude of these compressive stresses increases with the thickness of the CBS. After running a probabilistic analysis, it was determined that the extent of degradation found in this study is on average $5 \%$ of the CBS thickness, with a maximum value close to $20 \%$. To balance the high compression zone, the back of the CBS is subject to tension. The significance of this tension must be addressed in the future since this model does not account for energy dissipation caused by cracking or relaxation.

Using the irradiated concrete properties modeled in Le Pape [2015], Bruck et al. [2019] developed a finite element model accounting for the presence of the reinforcement and the considered concrete failure caused by overstresses. Once again, the results of this study show compression damage of the concrete most exposed to irradiation and tension damage at the back of the CBS. Damage extents are not provided.

More recently, Khmurovska et al. [2019] studied the long-term effects of irradiation on a VVER-440/213 CBS using a finite element model. VVER CBS included a $70 \mathrm{~cm}$-thick serpentine shield facing the reactor cavity and a $2.5 \mathrm{~m}$ structural concrete. Irradiation-induced, thermal, and mechanical damages are cumulated using an approach similar to Pomaro et al. [2011]. Irradiated concrete properties follow the suggestion from Le Pape [2015]. Mazars and Pijaudier-Cabot's model is assumed to account for mechanical damage; B3model for creep [Bažant and Jirásek, 2018]. The simulation results show the formation of vertical cracks propagating from the top of the CBS where the thickness is reduced. These cracks are caused by the gradual "vase"-shaped deformation induced by the expansion of the serpentine shield.

Finally, Kambayashi et al. [2020] developed a lattice-based meso-scale model of a portion of a prototypical CBS. Aggregates and reinforcing bars are explicitly represented. Cracking and creep occur in the mortar phase surrounding the aggregates subject to RIVE. Thermal strains are also taken into account. This study confirms the occurrence of large compressive stresses near the reactor cavity causing cracking parallel (spalling effect) to the inner surface of the concrete wall. Cracking extends beyond the location of the inner vertical and circumferential rebars, reaching a depth of about $200 \mathrm{~mm}$, although crack opening is considerably reduced beyond the rebar when compared to cracking in the concrete cover (distance to rebar center: $100 \mathrm{~mm}$ ). Giorla et al. [2016], using a comparable meso-scale finite element model, concluded that the penetration of damage reached about $150 \mathrm{~mm}$ after 80 years of operation. This study did not find detrimental tensile stress at the back of the CBS as the result of mortar's relaxation and stress redistribution in the reinforcement.

In conclusion, the literature analysis determined that irradiation-induced damage in a PWR CBS combines two forms of damage: (1) direct degradation resulting from irradiation-induced damage causing microcracking in the concrete constituent, and (2) mechanical damage caused by large vertical and circumferential stresses resulting from the structurally restrained radiation-induced volumetric expansion. Although these effects are not identical, they are analogous to those produced by ASR. Therefore, the proposed modeling 
strategy relies on using the ASR model that is already implemented in Grizzly.

\subsection{Transferring Fluence from VERA to Grizzly}

The fluence from VERA is transferred to Grizzly using an Exodus II file (Schoof and Yarberry [1994]). Exodus files are used to store mesh and field data for finite element analysis codes and for codes that use unstructured meshes. It is supported for use within Grizzly and other MOOSE-based codes. A cylindrical mesh is set up to overlay the RPV liner, RPV, gap, bioshield liner, and the bioshield. The fluence is stored for every node in that mesh, and then a finite element interpolation within Grizzly is used for damage/embrittlement studies to evaluate the fluence values throughout the different regions encompassing this mesh (Spencer et al. [2019]).

Since VERA does not output results in Exodus II file format, a standalone Python script was written in 2019 to support VERA-Grizzly coupling for vessel fluence calculations under the CASL program (Spencer et al. [2019]). The VERA fluence tally mesh exists on a cylindrical volume mesh, which can make translation to the Exodus mesh difficult. For this work, the nodes in the Exodus mesh are directly mapped into the VERA volume mesh to determine the fluence assigned to that node. In many cases, the node exists on a surface between two volumes in the VERA mesh, so the script defaults to rounding down; however, rounding differences can cause some subtle differences in mapping, predominantly in the radial direction. This was mitigated by applying a small tolerance to the mapping routine which greatly reduced the impact of rounding differences. In this work, this script was also modified to accumulate the fluence over different cycles and to also account for the extrapolation of fluence for several cycles into the future.

\subsection{Grizzly simulation setup}

\subsubsection{Mesh generation}

For the purpose of this work, the Grizzly model only includes the CBS and its stainless-steel liner. The fluence decreases almost exponentially with depth in the CBS, and it is concentrated around the inner surface. To model degradation at the inner volume of the CBS more accurately, the mesh used in the Grizzly simulation was refined near the CBS's inner surface using 30 radial elements for the CBS. The elements are thinner at the inner region of the CBS, and they grow toward the outer surface with a growth factor of 1.1. The AnnularMeshGenerator and MeshExtruderGenerator MOOSE mesh tools were used to generate and extrude the annular mesh. A single radial element was used for the CBS liner. The number of axial elements is 30 for both the CBS and its liner. The geometry of the hollow cylinders representing the CBS and its liner is identical to that used to map the fluence. The resulting mesh is shown in Fig. 19: the red and gray blocks represent the liner and the CBS, respectively. The CBS and liner meshes are then connected using the StitchedMeshGenerator tool to form a single mesh. A side set corresponding to the bottom surfaces of the CBS and its liner were added to the mesh using the SideSetsFromPointsGenerator tool in MOOSE. The biological shield extends to lower elevation to be supported by the containment building basemat. Since only a limited portion of the biological shield is modeled in this study, a choice was made regarding the boundary conditions at the bottom of the model. At this elevation, the fluence remains high, so perfectly pinned conditions $\left(u_{x}=u_{y}=u_{z}=0\right)$ would lead to an unrealistic RIVE-induced bending moment at the base of the model which would cause the base to fracture. 


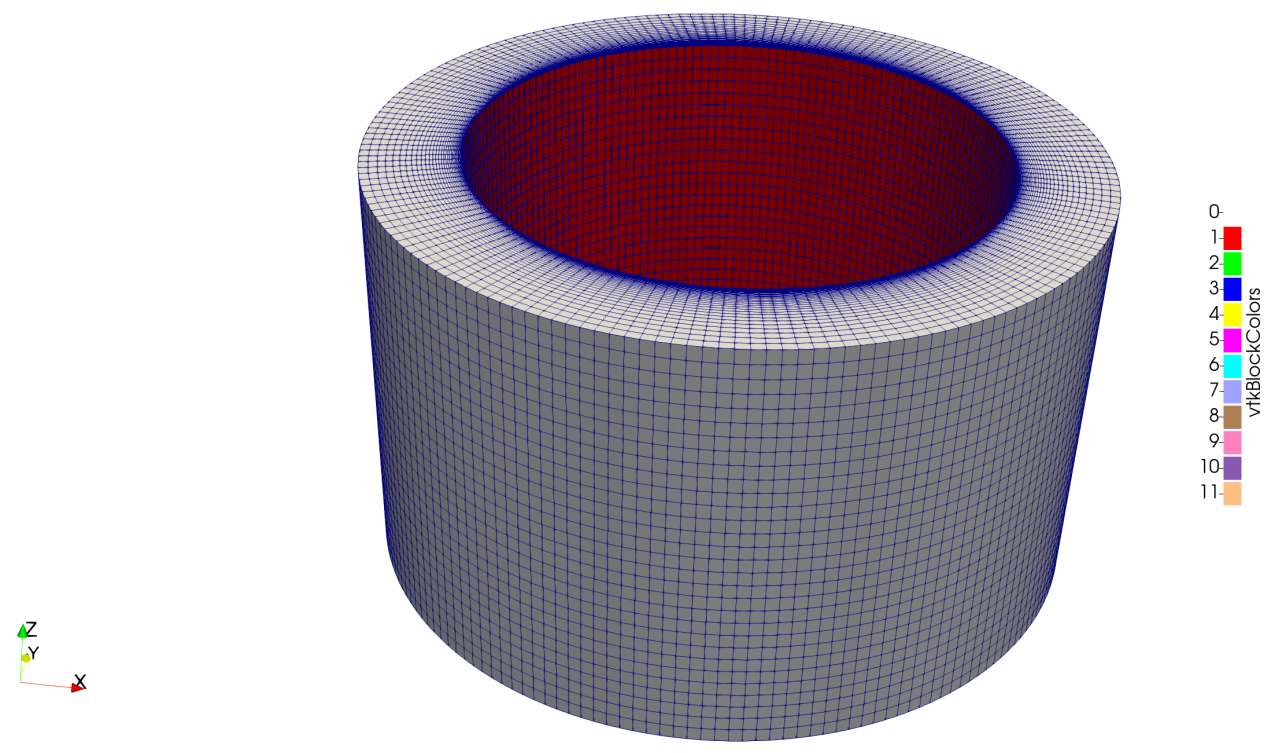

Figure 19. Representative mesh and geometry generated to simulate radiation-induced degradation in the CBS.

\subsubsection{Elastic properties}

A linear elasticity model is used in the CBS liner, for which Young's modulus is $200 \mathrm{GPa}$, and Poisson's ratio is 0.3. The CBS is assumed to have a long-term Young's modulus of $15 \mathrm{GPa}$ and a Poisson's ratio of 0.2. While the instantaneous Young's modulus of structural concrete is typically on the order of 40-45 GPa, the concept of a long-term modulus is commonly adopted when modeling concrete structures which are subject to slow-rate loading without accounting explicitly for creep phenomenon. It is generally assumed that the long-term modulus is about a third of the instantaneous modulus. Such an empirical approach is only acceptable for preliminary studies and does not replace an explicit modeling of delayed deformation. If an instantaneous Young's modulus of concrete is assumed, then it is set to $36.9 \mathrm{GPa}$. This value is taken from the work by Kommendant et al. [1976] and will be used in the logarithmic creep model following the approach of Torrenti and Le Roy [2018].

In the presented simulations, an isotropic RIVE model, a logarithmic creep model, and mechanical and micromechanical damage models are used.

\subsubsection{RIVE model}

RIVE is caused by the amorphization-induced change of density of the aggregate-forming minerals. The amplitude of RIVE varies greatly with the mineralogy but can reach several percents at high fluence (> $10^{19} \mathrm{n} . \mathrm{cm}^{-2}$ at $E>0.1 \mathrm{MeV}$ ). For this demonstration study, the RIVE's parameters are from Le Pape [2015] who provided a fitted RIVE model for concrete using Zubov's equation form (Zubov and Ivanov [1966a]). These parameters correspond to the average response of a representative subset of literature data 


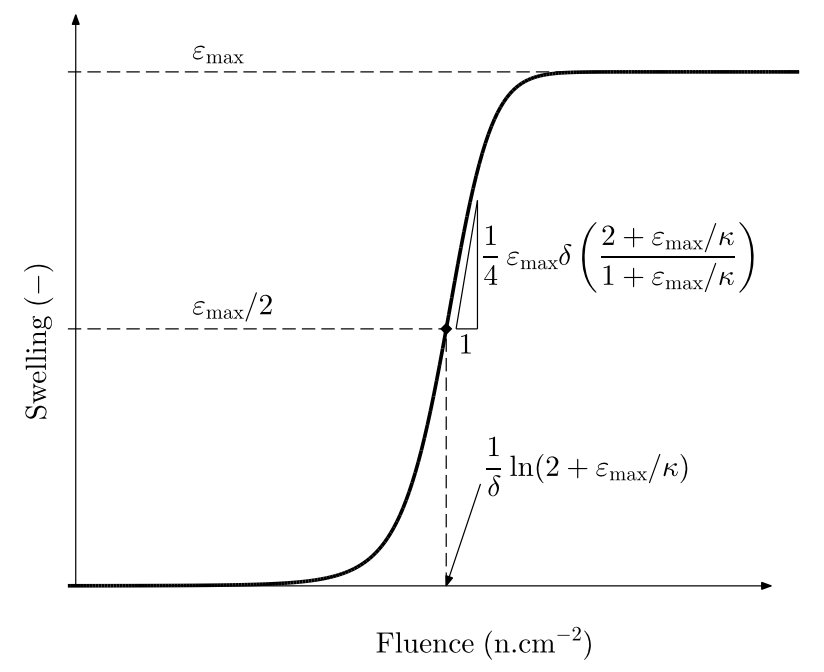

Figure 20. Characteristics of Zubov's swelling curve.

collected by Field et al. [2015]. The model expression evolves with neutron fluence, is dependent on the maximum amplitude of RIVE and other fitting parameters, and does not depend on the temperature, which is a simplification since it does not account for annealing effects. As a first approximation, Zubov and Ivanov [1966b]'s equation reads

$$
\varepsilon^{*}(\Phi)=\kappa \varepsilon_{\max } \frac{e^{\delta \Phi}-1}{\varepsilon_{\max }+\kappa e^{\delta \Phi}} .
$$

The terms $\varepsilon_{\max }$ are the maximum expansion, and $\kappa$ (dimensionless parameter homogeneous to a strain) and $\delta$ (inverse of a fluence) govern the shape of the sigmoid. In particular, the inflexion point of the sigmoid corresponds to a fluence of $\frac{1}{\delta} \ln \left(2+\varepsilon_{\max } / \kappa\right)$ and a swelling of half of the maximum amplitude: $\varepsilon_{\max } / 2$. Other characteristics of Zubov's curve are provided in Fig. 20. It can be observed that, except for the final amplitude of swelling, the main characteristics of Zubov's curve do not show a one-to-one dependency on Zubov's model parameters. The best-fit parameters of the Zubov function were obtained by linear regression: $\varepsilon_{\max }=0.936 \%, \kappa=0.968 \%, \delta=3.092 \times 10^{-20} \mathrm{n}^{-1} \mathrm{~cm}^{2}$. This model was used in this research to calculate the eigenstrain resulting from RIVE in the CBS. The fluence is read as a function in the Grizzly input file from the mesh file generated using the VERA fluence calculations described in Section 4.2 using SolutionUserObject and SolutionFunction in MOOSE. The fluence function is then attributed to an auxiliary variable in Grizzly and is used in the RIVE eigenstrain calculations.

The VERA fluence was calculated for neutron energies $E_{n}$ higher than $1 \mathrm{MeV}$; however, the model uses a cutoff energy of $0.1 \mathrm{MeV}$. To account for the higher fluence at $E_{n}>0.1 \mathrm{MeV}$, the VERA fluence is multiplied by 10, which is an estimated fluence factor for a four-loop PWR based on the work by Remec [2013]. 


\subsubsection{Damage models}

RIVE in concrete and the application of the no-displacement boundary condition at the bottom of the structure result in high levels of compressive and tensile stresses in the CBS. In this work, the mechanical damage from these stresses is modeled using the isotropic scalar damage model developed by Mazars [1986]. Furthermore, the development of RIVE in the structure causes micro-cracking that results from the local macroscopic swelling of aggregates in the concrete. A micromechanical damage model is available in Grizzly to account for internal expansions such as RIVE and ASR. The model considers unconfined, confined, and mixed conditions. Both the mechanical and micromechanical damage models are used in this work, in which the total damage variable is taken as the maximum of both damage variables. The total damage variable is referred to as the combined damage.

4.3.4.1 Mazars damage model Mazars's model is a simple but robust isotropic damage model for concrete which makes it possible to account for the loss of stiffness of concrete caused by cracking under both uniaxial tension and uniaxial compression by means of a unique scalar damage variable $d$. Damage depends only on the effective stresses applied to an undamaged area. Although compression and traction damage are controlled by a similar mathematical expression, it can replicate the quasi-brittle (rapid softening) behavior in tension and the more "ductile" behavior in compression when model parameters are chosen adequately. Grizzly's version of the Mazars model is local, meaning that it does not include regularization (or "non-local") techniques to account for the energy dissipation in the cracking process zone. This issue is predominant in areas where strong localization occurs (fracture). In Grizzly, the model requires six model parameters: the concrete tensile strength, the elastic modulus, and the parameters $A_{c}, B_{c}, A_{t}$, and $B_{t}$. Parameters $A_{c}$ and $B_{c}$ control the damage variable in compression, and $A_{t}$ and $B_{t}$ control the damage variable in tension. The model parameters used in this work are presented in Table 3.

4.3.4.2 Micromechanical damage model The Mazars model only accounts for mechanical damage caused by excessive stresses. Therefore, when the model is applied to free-expanding materials subject to eigenstrains (i.e., RIVE), any mechanical damage model will predict the absence of damage. However, when subject to high levels of neutron irradiation, even an unconstrained concrete specimen exhibits a loss of mechanical properties (Denisov et al. [2012]). To determine the micromechanical damage model parameters, the modeled loss of elastic modulus with neutron fluence in unconfined conditions was compared to the fitted expression of the loss of modulus developed in Le Pape [2015] based on experimental data. Based

on this comparison, the microcracking is set to initiate at a strain of $10^{-5}$. Additionally, the microcracking strain branch parameter controls the rate of damage with RIVE. In confined conditions in the CBS, the expansion stress limit in the model strongly affects the loss of modulus with fluence. A semi-arbitrary value of $40 \mathrm{MPa}$ was chosen for this parameter to avoid rapid damage development. The micromechanical damage model parameters are given in Table 3.

\subsubsection{Creep model}

Although the biological shield is not a post-tensioned structure, modeling-delayed "viscous" mechanisms are necessary to account for the energy dissipation through the relaxation of the highly irradiated concrete 
Table 3. Damage model parameters used in Grizzly

\begin{tabular}{c|c|c} 
Model & Parameter & Value \\
\hline Mazars damage model & Tensile strength $(\mathrm{MPa})$ & 5 \\
& $A_{c}$ & 1.75 \\
$B_{c}$ & 2,000 \\
$A_{t}$ & 0.87 \\
& $B_{t}$ & 8,000 \\
\hline Micro-damage model & Microcracking initiation strain & $10^{-5}$ \\
& Microcracking strain branch & $1.266 \times 10^{-2}$ \\
& Expansion stress limit (MPa) & 40
\end{tabular}

Table 4. Logarithmic creep model parameters from Torrenti and Le Roy [2018] and Kommendant et al. [1976]

\begin{tabular}{c|c} 
Parameter & Value \\
\hline$t_{0}($ year $)$ & 1 \\
$E\left(t_{0}\right)(\mathrm{GPa})$ & 36.9 \\
$\beta_{1}$ & 0.7 \\
$\beta_{2}$ & 0.2 \\
$C(\mathrm{GPa})$ & 29.4 \\
$\tau\left(t_{0}\right)$ (year) & 0.1176
\end{tabular}

subject to large compression. When delayed strains are not accounted for, the energy dissipation is only associated with damage development (cracking). Work performed by Vandamme and Ulm [2009] and Bažant and Baweja [2000] has shown that the long-term creep strain in concrete increases logarithmically with time. The implementation of the concrete logarithmic creep in Grizzly was performed and documented in the work by Giorla [2017]. For the purpose of this work, a long-term logarithmic creep model is used following the equation for the compliance $J$ given by Torrenti and Le Roy [2018]:

$$
J\left(t_{0}, t-t_{0}\right)=\frac{1}{E_{0}}+\frac{1}{\beta_{1} C} \log \left(1+\frac{t-t_{0}}{\beta_{2} \tau\left(t_{0}\right)}\right),
$$

where $t_{0}$ is the age of loading, $t$ is time, $E\left(t_{0}\right)$ is Young's modulus at the age of loading, $\tau\left(t_{0}\right)$ is the characteristic time, and $\beta_{1}, \beta_{2}$, and $C$ are parameters calculated based on experimental results. Based on the equations determining $C$ and $\tau_{0}$ in Torrenti and Le Roy [2018] and data from Kommendant et al. [1976], the model parameters used in this work are presented in Table 4.

The long-term irrecoverable logarithmic creep model in Grizzly depends on four parameters:

- Young's modulus $E_{0}$,

- Poisson's ratio $v$,

- Long-term viscosity $\eta_{v}$, and

- Long-term characteristic time $\tau_{v}$.

These parameters are calculated based on the model parameters in Table 4 and are given in Table 5. The time-dependent parameters are adjusted to account for the high fluences calculated in VERA, so it is assumed 
Table 5. Elastic term and irrecoverable basic creep model parameters used in Grizzly

\begin{tabular}{c|c} 
Parameter & Value \\
\hline$E_{0}(\mathrm{GPa})$ & 36.9 \\
$v$ & 0.2 \\
$\eta_{v}$ (year) & $1.64 \times 10^{-4}$ \\
$\tau_{v}$ (year) & $1.47 \times 10^{-3} \beta_{2}$
\end{tabular}

that when VERA calculations result in a maximum fluence of $5.7 \times 10^{19} \mathrm{n} / \mathrm{cm}^{2}$, the corresponding time is 80 years.

The corresponding compliance function $J$ is expressed as

$$
J(t)=\frac{1}{E_{0}}+\frac{\tau_{v}}{E_{0} \eta_{v}} \log \left(1+\frac{t}{\tau_{v}}\right)
$$

Recoverable creep, as well as temperature and humidity dependencies in the model, are not considered in this work for simplicity.

\subsection{Results}

Four simulations were conducted:

1. Mazars model, with the initial Young's modulus being the instantaneous modulus $\left(E_{0}\right)$ (Case 1$)$;

2. Mazars model, with the initial Young's modulus being the delayed modulus $\left(\approx E_{0} / 3\right)($ Case 2$)$;

3. Mazars model, with the initial Young's modulus being the delayed modulus $\left(\approx E_{0} / 3\right)$ and, adding the effects of micro-damage caused by irradiation (Case 3);

4. Mazars model, with the initial Young's modulus being the instantaneous modulus $\left(E_{0}\right)$, micro-damage and creep (Case 4).

The final maximum fluence in the simulation is $5.7 \times 10^{19} \mathrm{n} / \mathrm{cm}^{2}$ for $E_{n}>0.1 \mathrm{MeV}$, as estimated in this work. The simulations in Cases 1 and 2 were successfully performed up to the final fluence. In Cases 3 and 4, the solve did not converge up to the end time (assumed to be 80 years), but rather, up to nearly 40 and 54 years, respectively. Note that temperature and humidity are not used in the present models. Therefore, this analysis is based on rather simple models, and future work will include further complexities such as heat and moisture diffusion, as well as the inclusion of rebar.

An example fluence map obtained from VERA in the CBS is shown in Figure 21. The highest fluence is concentrated on the inner surface and drops rapidly with depth. The micromechanical damage is located in this area because it is strongly relates to the eigenstrain from RIVE. The mechanical damage depends on the tensile and compressive stresses in the structure and predicts cracking caused by the high compressive stresses at the highest fluence areas. Figure 22 illustrates these results through example damage fields extracted from the Case 3 simulation at a maximum fluence of $2.5 \times 10^{19} \mathrm{n} / \mathrm{cm}^{2}$.

To illustrate the difference between the damage models in Cases 1-4, the radial profiles of the combined damage at mid-height are shown in Figure 23 at the time step corresponding to a maximum fluence of 


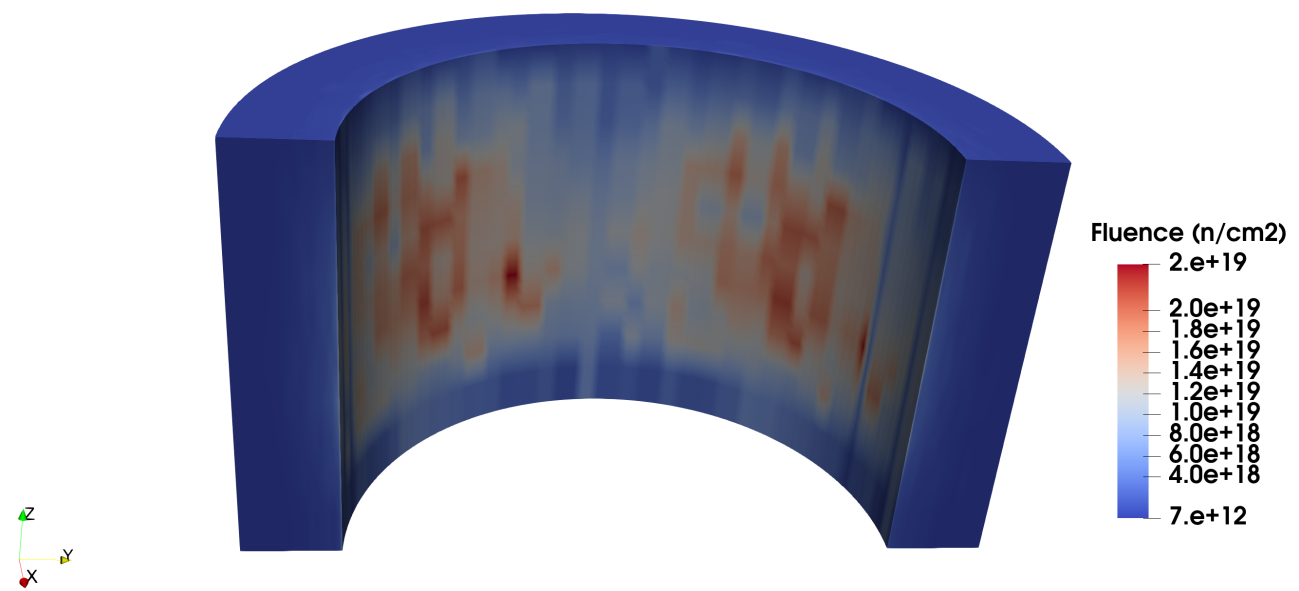

Figure 21. Example fluence map $\left(\mathrm{n} / \mathrm{cm}^{2}\right.$ for $\left.E_{n}>0.1 \mathrm{MeV}\right)$ in a clipped domain of the CBS.

$2.5 \times 10^{19} \mathrm{n} / \mathrm{cm}^{2}$ in the CBS structure. The $x$ and $y$ interval used to plot the radial profiles is [-2.47487,$1.8275] \mathrm{m}$ at $z=2 \mathrm{~m}$. As the plots show, at this stage of the simulation, Case 3 presents the most damage at the inner surface of the CBS. Case 1 shows that damage has developed near the outer surface of the CBS, which is not predicted in Cases 2 and 3. In fact, Case 1 constitutes the simplest model and therefore is less representative of the degradation in the CBS than the other Cases. Furthermore, Cases 2 and 3 show a major difference; the inclusion of the micro-damage allows for further in-depth damage propagation. Therefore, the use of the Mazars model alone is not sufficient to predict the concrete's degradation beyond the inner surface. This degradation is obtained up to approximately half of the CBS depth. Case 4 predicts an onset of damage near the back of the structure. However, the overall damage remains lower with the addition of the creep model.

The damage in the CBS for the four cases is illustrated in 24 at a maximum fluence of $3.6 \times 10^{19} \mathrm{n} / \mathrm{cm}^{2}$ $\left(E_{n}>0.1 \mathrm{MeV}\right)$ and after approximately 40 years of irradiation. Case 1 predicts the most damage in the CBS, where cracks develop at the upper surface and propagate towards the back of the CBS. These cracks result from the high tensile stress at the upper surface. Case 2 shows less overall damage than Case 3; however, both cases only show damage in the interior surface at this fluence level (corresponding approximately to 40 years of irradiation). Case 4 uses the instantaneous elastic modulus, in addition to a concrete creep model, and it predicts that damage also develops on the top surface of the CBS, in addition to the inner surface.

\subsection{Run times and computing resources}

The Idaho National Laboratory high-performance computing resources were used to conduct the Grizzly simulations. Between 36 and 72 cores over one to two cluster nodes were used for all simulations. The run times are shown in Table 6. 


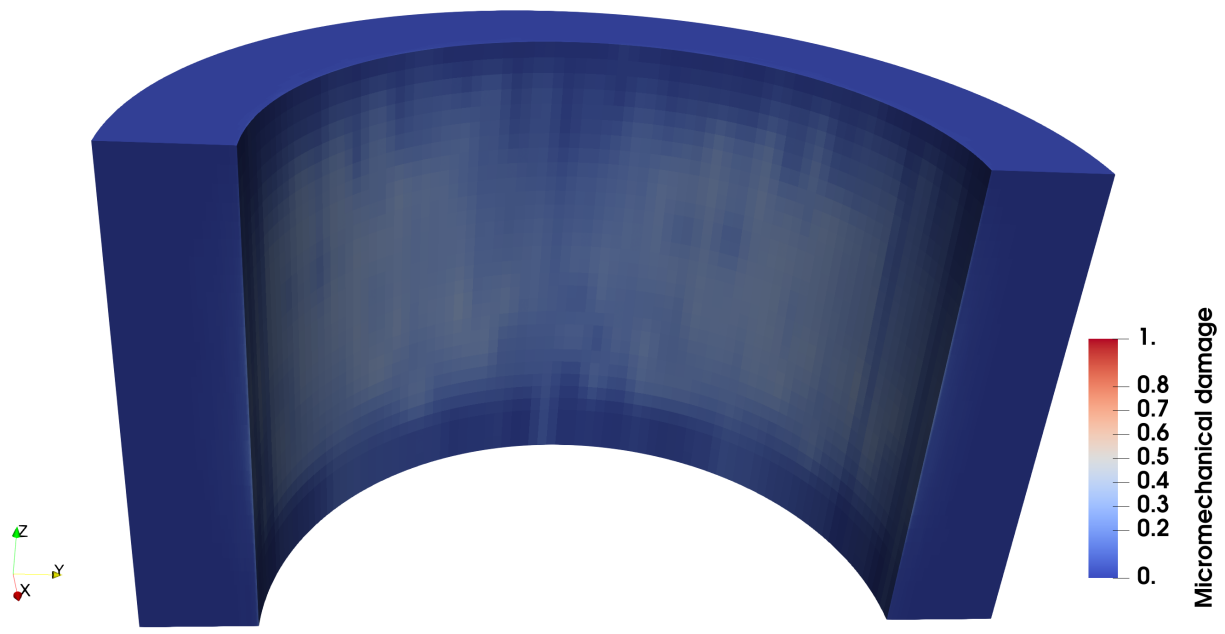

(a) Micromechanical damage

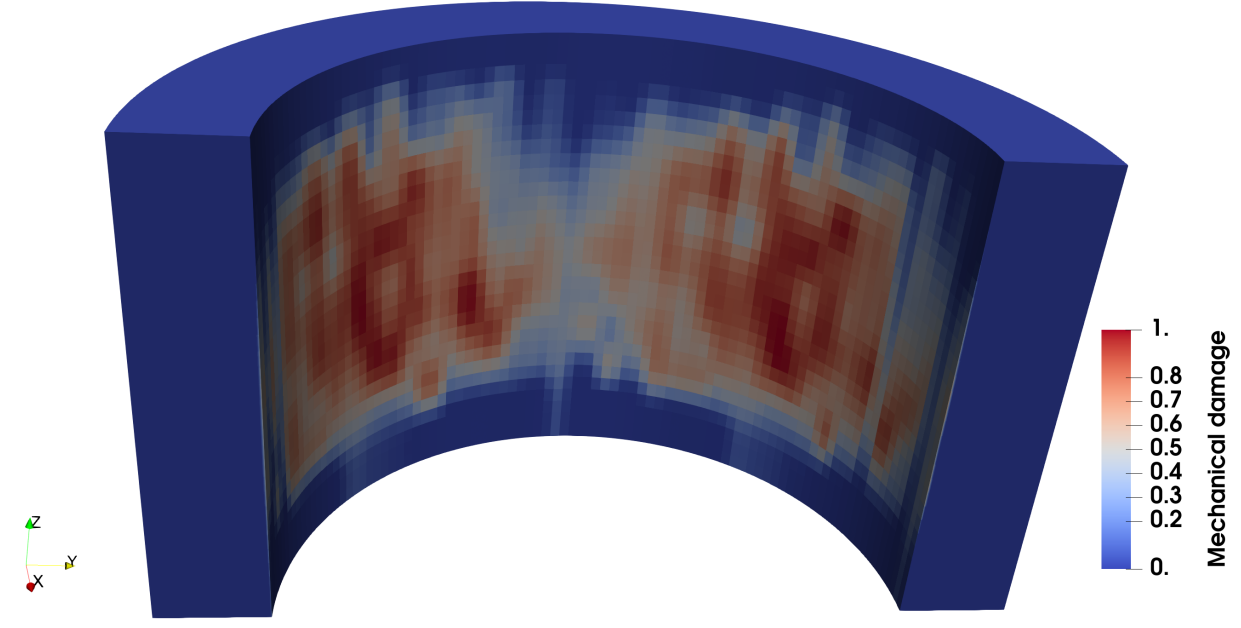

(b) Mechanical damage

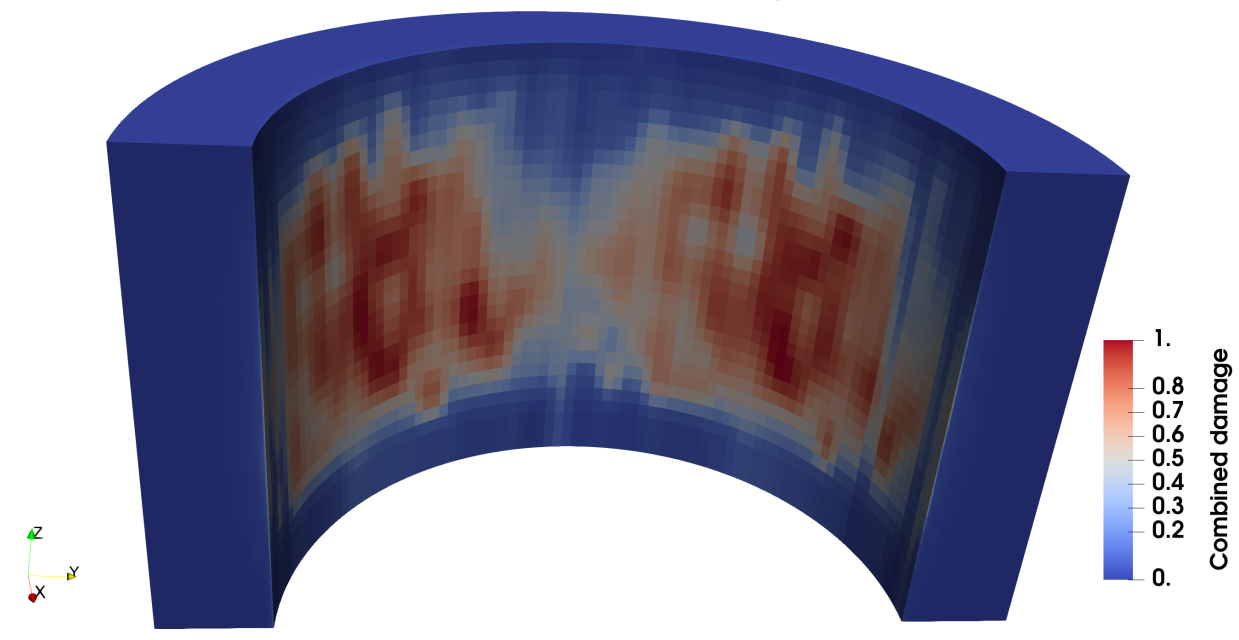

(c) Combined damage

Figure 22. Example clipped damage fields taken from Case 3 at maximum fluence $2.5 \times 10^{19} \mathbf{n} / \mathrm{cm}^{2}$. 


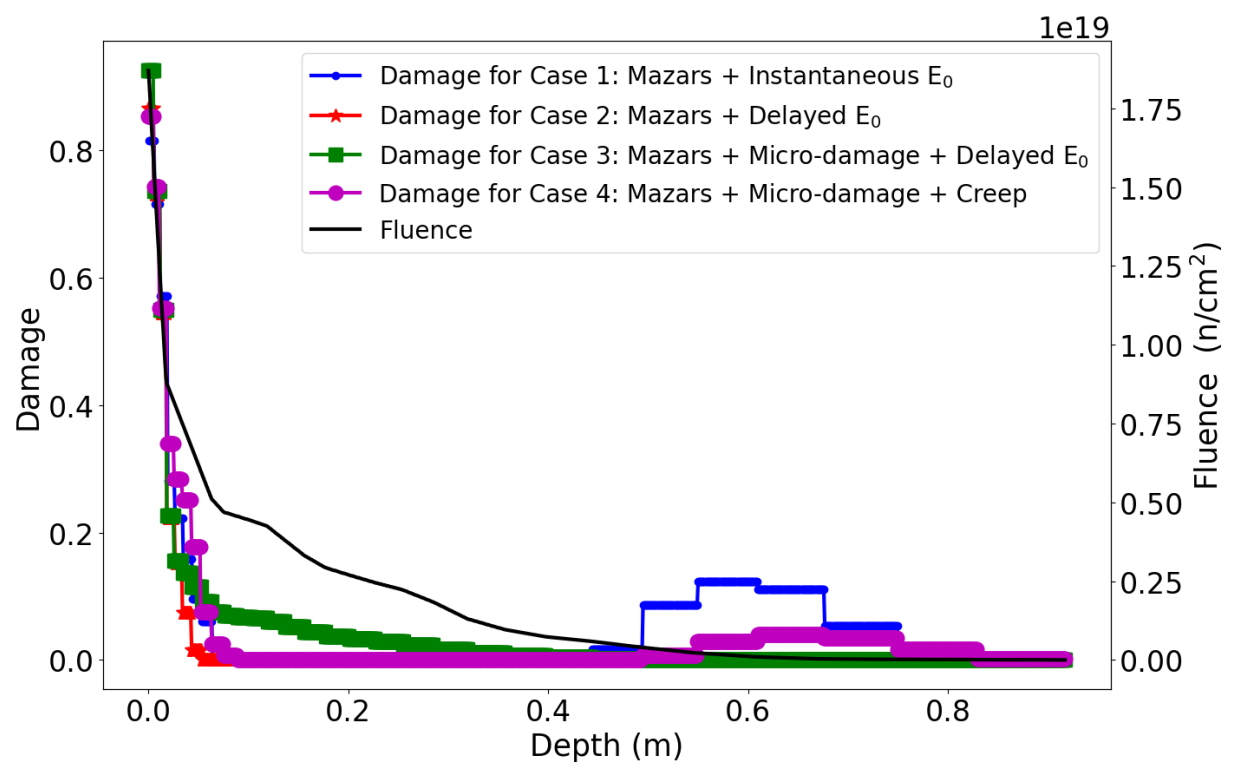

Figure 23. Damage (left axis) and fluence (n/cm ${ }^{2}$ for $E_{n}>0.1 \mathrm{MeV}$ ) (right axis) evolution with depth in the CBS.

\begin{tabular}{c|c} 
Case & Run time (hh:mm:ss) \\
\hline Case 1 & $05: 04: 19$ \\
Case 2 & $05: 29: 29$ \\
Case 3 & $15: 38: 38$ \\
Case 4 & $09: 54: 37$
\end{tabular}

Table 6. Run times by case. 


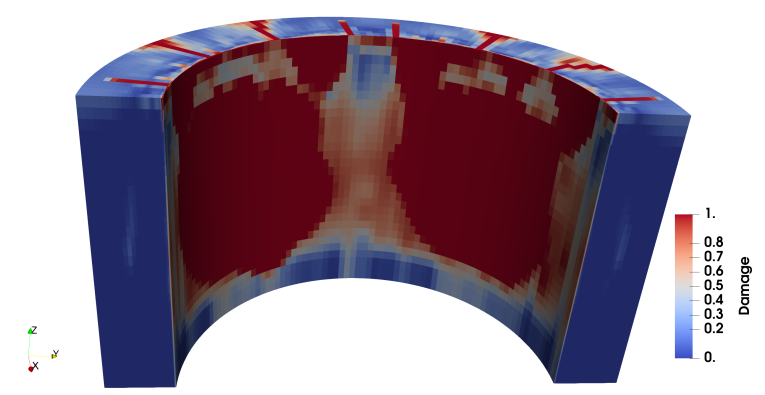

(a) Case 1

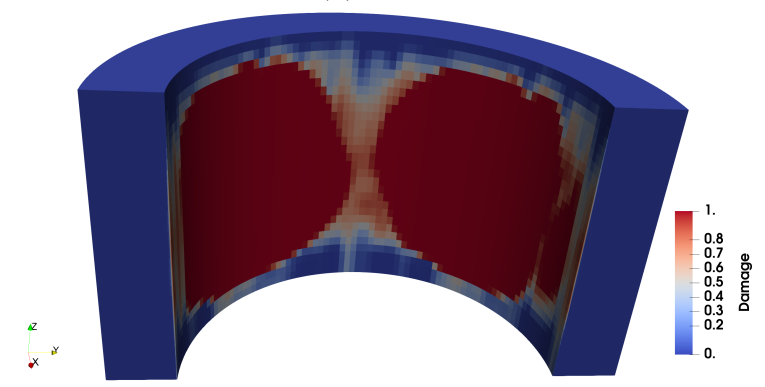

(b) Case 2

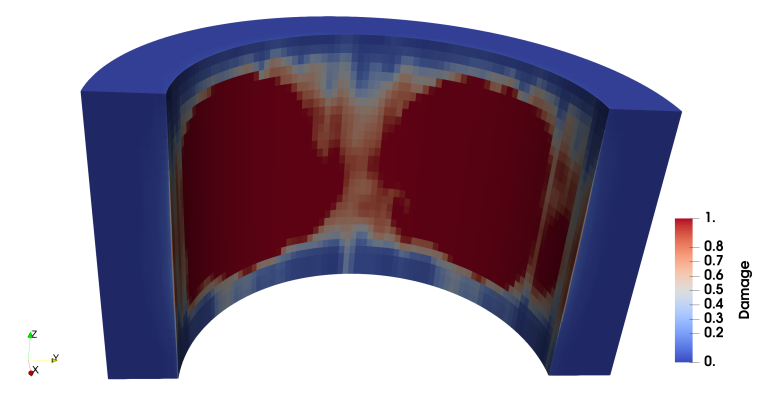

(c) Case 3

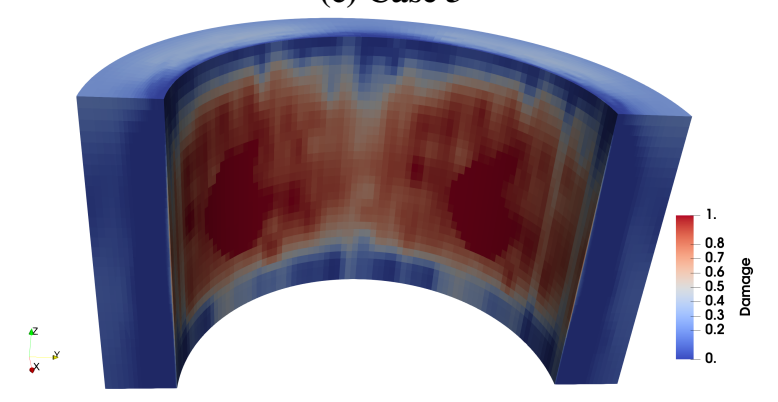

(d) Case 4

Figure 24. Clipped damage fields at maximum fluence $3.6 \times 10^{19} \mathrm{n} / \mathrm{cm}^{2}\left(E_{n}>0.1 \mathrm{MeV}\right)$ and approximately 40 years of irradiation. 


\section{CONCLUSION}

WBN1 Cycle 1 and 2 inputs were run successfully in VERA to generate the fluence data to pass on for further concrete material degradation studies in Grizzly. The fluence data were passed to Grizzly using a Python script. The concrete bioshield was truncated in the VERA models because the statistical uncertainty in the flux further into the concrete was high. The fluence data from this truncated grid were passed to Grizzly. However, it was noted during this work that it is important to keep the grid between VERA and Grizzly the same to prevent the need to make any extrapolations in the fluence data. The workflow for passing fluence from VERA to Grizzly in the concrete bioshield was established in this work. Fluence calculated for WBN1 indicate that they are higher than expected in the vessel and bioshield. This issue was reported to the developers and is currently being investigated by the development team. The models and the parameters used in the definition of the vessel and the bioshield in the VERA input were scrutinized however, the issue needs further investigation. From the VERA calculations performed for this study, the following points were concluded:

1. There is no advantage to running vessel and bioshield fluence calculations with FW-CADIS rather than CADIS when optimizing for a single cell in the bioshield. FW-CADIS aims to uniformly reduce the statistical error over multiple tally regions, unlike CADIS. However, performance improvements with FW-CADIS are expected if optimizing for flux in specific energy ranges (e.g. fast and epithermal flux) on a mesh tally in the bioshield instead of a single cell.

2. To avoid running into memory issues with FW-CADIS calculations, the user may want to consider using CADIS with a larger mesh tally and running more particle histories to increase the chances of scoring in the tally region.

3. The grid on which the fluence data is passed to Grizzly will be coarse. It is important to keep the grid between the Shift tally and the Grizzly model the same. This allows for the proper accounting of physics in the Grizzly model without having to extrapolate from the VERA fluence data.

4. If the fluence data from VERA are passed to Grizzly on a coarser grid to reduce statistical uncertainty, then a smoothing function or interpolation of some sort may need to be applied.

Further testing on the WBN1 models showed that performance improvements are needed for the coupled neutron-photon Shift calculations in VERA. It is important to account for gamma heating for vessel and bioshield fluence calculations, and performance improvements to these coupled neutron-photon calculations would help produce the fluence data and heating tallies needed to perform relevant materials degradation analysis with Grizzly.

The fluence results obtained by VERA were successfully transferred to Grizzly to run a preliminary nonlinear structural analysis of the effects of irradiation on the development of damage in the concrete biological shield. The temperature and moisture content fields (radial profile) were assumed. The biological shield is assumed to be unreinforced. Four models were created with:

1. Mazars mechanical damage model, with the initial Young's modulus being the instantaneous modulus $\left(E_{0}\right)($ Case 1);

2. Mazars mechanical damage model, with the initial Young's modulus being the delayed (long-term) modulus $\left(\approx E_{0} / 3\right)($ Case 2$)$; 
3. Mazars mechanical damage model, with the initial Young's modulus being the delayed modulus $(\approx$ $E_{0} / 3$ ) and, adding the effects of micro-damage caused by irradiation (Case 3);

4. Mazars mechanical damage model, with the initial Young's modulus being the instantaneous modulus $\left(E_{0}\right)$, micro-damage and creep (Case 4).

The simulations were conducted up to a maximum fluence of $5.7 \times 10^{19} \mathrm{n} . \mathrm{cm}^{-2}$ at $E>0.1 \mathrm{MeV}$ at the surface of the concrete, a value considered conservative for 4-loop PWRs (Esselman and Bruck [2013]). The results of the simulation are consistent with previous literature studies (Pomaro et al. [2011], Salomoni et al. [2014], Andreev and Kapliy [2014], Le Pape [2015], Giorla et al. [2016], Bruck et al. [2019], Kambayashi et al. [2020]).

Three modes of degradation are observed:

1. The portion of the CBS exposed to the high fluence near the reactor cavity is subjected to degradation caused by direct irradiation-induced damage and mechanical damage caused by the development of biaxial (vertical and circumferential) compressive stresses induced by the restrained RIVEs (structural effect). Damage extends beyond the depth of the reinforcing bars.

2. The back portion of the biological shield is subject to tensile stresses balancing the high compressive stresses near the reactor cavity. Tensile damage occurring in this area is greatly influenced by the actual thickness of the biological shield, which was truncated in this analysis because VERA simulations could not achieve statistically reliable data beyond $\approx 1.5 \mathrm{~m}$. It is expected that extending the thickness of the biological shield to its actual dimension will reduce the tensile stresses amplitude and thus will reduce the damage extent.

3. At a later stage of the simulation, vertical cracking occurs radially at the top of the CBS. These cracks propagate toward lower elevations as RIVE increases in the shield inner portion. This mechanism has been observed in previous studies (Khmurovska et al. [2019]) and is exacerbated when the stiffness of the concrete is higher (i.e., when delayed "viscous" strains are not accounted for). 


\section{FUTURE WORK}

VERA-Shift optimization The high fluences seen from the VERA Shift WBN1 calculations need to be investigated further. The models and the code need to be assessed in greater detail to idenfity the issue. In addition, the advantage of using FW-CADIS will be more apparent when optimizing for a mesh tally instead of a single cell, in this case the outer ring of the bioshield, in VERA. It is currently not possible to optimize for a mesh tally in VERA Shift, therefore, future work could involve incorporating the ability to optimize for a mesh tally instead of a cell. In addition, the ability to optimize fluence calculations for the fast neutron flux instead of the total neutron flux would be beneficial in these calculations.

Concrete composition for neutronics calculations It is important to accurately account for the concrete composition in the bioshield. Because concrete compositions vary quite widely, an effort must be made to make the best approximation to the composition. For these calculations, it was assumed that the ORNL concrete from R. J. McConn Jr. et al. [2011] is used for the concrete bioshield. More generally speaking, the effect of moisture transport (drying and dehydration) affects the hydrogen content and thus affects irradiation transport. Coupling of irradiation transport, moisture transport, and heat transfer would improve the accuracy of the simulations.

Gamma irradiation, Moisture Transport and Heat Transfer The simulation presented in this report only accounts for the effects of neutron irradiation on the development of radiation-induced expansion and associated damage. Across the depth of the CBS, the moisture content was assumed to be constant, and the temperature field was assumed to be varying linearly. Gamma-irradiation moderately affects the structural properties of concrete, but associated gamma heating also contributes to the dehydration of concrete. Therefore, it is important to account for gamma heating in VERAShift calculations. Gamma transport calculations are currently slow in Shift and must be optimized, and heating rate tallies must be included to provide gamma heating data for concrete degradation studies. The irradiation-induced energy deposition creates an internal heat source that contributes to the elevation of temperature in the vicinity of the reactor cavity. Both temperature and moisture content affect the concrete properties and the kinetics of RIVE. Therefore, it is necessary to account for the coupled moisture transport and heat transfer in the model. Based on the works of Bažant and Thonguthai [1979], Xi et al. [1994] such a model was implemented in Grizzly in 2016 and is readily available. While the presence of a liner prevents moisture loss in the cavity, some PWR designs do not include a liner. In the latter case, moisture migration will have a preponderant effect on simulation results.

Structural Model The geometry of the CBS in the work is extremely rudimentary, and three areas require further attention. First, the boundary conditions at the bottom of the CBS have an effect on the stress field and must be accounted for. In reality, the CBS is connected to the containment basemat. Thus, the CBS model needs to be extended vertically, and the basemat needs to be included. Second, the thickness of the CBS was truncated in the VERA simulations for statistical accuracy of the neutron counts. From the perspective of structural analysis, the thickness of the CBS is critical to account for the actual distribution of the stresses' radial profiles. Reducing the thickness of the CBS causes excessive tensile stresses toward the back of the wall. Third, depending on the reactor design, the RPV nozzle rests on the RPV through anchored support. Although the RPV nozzle is located at a higher elevation than the most exposed concrete 
near the belt line, literature study [Bruck et al., 2019] has shown that long-term irradiation may affect the support function. More generally, the presence of the embedded reinforcement, mostly in the form of vertical and circumferential bars, must be included in the model since reinforcement participates actively in the redistribution of stresses in the structure. For the rebars and the anchors (e.g., liner-connecting studs) located in the highly exposed area, the effects of irradiation on the bond strength of the steel elements in concrete should be considered.

Concrete Constitutive Model The constitutive model in this preliminary study includes (1) a regular Mazars damage model to account for the effects of mechanical loading and (2) a micro-mechanical model to account for the effect of irradiation-induced expansion on the formation of microcracking. The accuracy of the simulation in the areas exhibiting fracture-like damage is questionable because the model is local. Implementing a non-local regularization of damage in Grizzly is highly recommended. The parameters for the micromechanical damage require validation data on the effects of confining stresses; these data are not available in the open literature. The parameters governing the RIVE of concrete must be specific to the concrete being studied, because important variations occur with the mineralogy of the aggregates. It is recommended that a sensitivity analysis be performed to assess the extent of damage progression in PWRs. Shrinkage, which was not considered in this work must be added to account for the dehydration of concrete caused by operation (irradiation-induced radiolysis). Although a preliminary creep model was introduced in the simulations, the chosen creep parameters are only relevant for concrete at room temperature and do not account for the coupled effects with irradiation. Limited literature research suggests that neutron-irradiation greatly affects the creep rate (McDowall [1971], Gray [1971]), and consequently, the development of damage in the biological shield.

Advanced Nuclear Reactors Although the research presented in this report is applied to LWRs, the proposed methodology is applicable to further advance the assessment of the integrity of future advanced reactors that may incorporate more concrete in the design for shielding approaches. 


\section{REFERENCES}

V.I. Andreev and D.A. Kapliy. Stress-State of a Thick-Walled Cylindrical Shell under the Combined Action of Radiation and Temperature Field. Advanced Materials Research, 1006-1007:177-180, 2014.

M. N. Avramova. CTF: A Thermal Hydraulic Sub-Channel Code for LWR Transient Analyses, User's Manual. Technical report, Pennsylvania State University Department of Nuclear Engineering, 2009.

P. Baggio, C.E. Majorana, and B.A. Schrefler. Thermo-Hygro-Mechanical Analysis of Concrete. International Journal for Numerical Methods in Fluids, 20:573-595, 1995.

Z.P. Bažant and S. Baweja. Creep and Shrinkage Prediction Model for Analysis and Design of Concrete Structures: Model B3. ACI Special Publication, 194:1-84, 2000.

Z.P. Bažant and M. Jirásek. Creep and Hygrothermal Effects in Concrete Structures, volume 225 of Solid Mechanics and Its Applications. Springer, 2018.

Z.P. Bažant and W. Thonguthai. Pore Pressure in Heated Concrete Walls: Theoretical Prediction. Magazine of Concrete Research, 31:67-76, 1979.

P.M. Bruck, T.C. Esselman, B.M. Elaidi, J.J. Wall, and E.L. Wong. Structural Assessment of Radiation Damage in Light Water Power Reactor Concrete Biological Shield Walls. Nuclear Engineering and Design, 350:9-20, 2019.

B. Collins and et al. MPACT VERA Input User's Manual Version 2.2.0. Technical Report CASL-U-20161109-000, CASL, June 2016.

E. E. Davidson, A. T. Godfrey, K. E. Royston, T. M. Pandya, S. C. Henderson, and T. M. Evans. IValidation of Light Water Reactor Ex-Core Calculations with VERA. accepted to appear in Nuclear Technology, $\mathrm{xx}: \mathrm{xx}-\mathrm{xx}, 2021$.

A.V. Denisov, V.B. Dubrovskii, and V.N. Solovyov. Radiation Resistance of Mineral and Polymer Construction Materials. ZAO MEI Publishing House, 2012. in Russian.

V.B. Dubrovskii, Sh.Sh. Ibragimov, A. Ya. Ladygyn, and B. K. Pergamenshchik. The Effect of Neutron Irradiation on Certain Properties of Refractory Concretes. Atomnaya Energiya, 21(4):108-112, December 1966. English Translation.

T. Esselman and P. Bruck. Expected Condition of Concrete at Age 80 of Reactor Operation. Technical Report A13276-R-001, Lucius Pitkins, Inc., 36 Main Street, Amesbury, MA 01913, September 2013.

T.M. Evans, A.S. Stafford, R.N. Slaybaugh, and K.T. Clarno. Denovo-A new three-dimensional parallel discrete ordinates code in SCALE. Nuclear Technology, 171:171-200, 2010.

K.G. Field, I. Remec, and Y. Le Pape. Radiation Effects on Concrete for Nuclear Power Plants - Part I: Quantification of Radiation Exposure and Radiation Effects. Nuclear Engineering and Design, 282: 126-143, 2015.

Kazushige Fujiwara, Masanobu Ito, Miwa Sasanuma, Hideo Tanaka, Kiyoshi Hirotani, Kunio Onizawa, Masahide Suzuki, and Hiroo Amezawa. Experimental Study of the Effect of Radiation Exposure to Concrete. In Proceedings of the 20th International Conference on Structural Mechanics in Reactor Technology, volume SMiRT 20 - Division I, Espoo, Finland, 2009. 
Cole Gentry, Benjamin Collins, Eva Davidson, Gregory Davidson, Thomas Evans, Andrew Godfrey, Shane Hart, Germina Ilas, Seth Johnson, Kang Seog Kim, Scott Palmtag, Tara Pandya, Katherine Royston, William Wieselquist, and Gary Wolfram. Secondary-Source Core Reload Modeling with VERA. Nuclear Science and Engineering, 0(0):1-18, 2020. doi: 10.1080/00295639.2020.1820797.

B. Gérard, G. Pijaudier-Cabot, and C. Laborderie. Coupled Diffusion-Damage Modelling and the Implications on Failure Due to Strain Localization. International Journal of Solids and Structures, 35(31-32): 4107-4120, 1998.

A. Giorla, Y. Le Pape, and H. Huang. Meso-Scale Modeling of Irradiation in Pressurized Water Reactor Concrete Biological Shield. In V. Saouma, J. Bolander, and E. Landis, editors, Proceedings of FraMCoS9, Berkeley, CA, May-June 2016. IA-FraMCoS. doi: 10.21012/FC9.238. URL http://www.framcos.org/ FraMCoS-9.php\#gsc.tab $=0$.

Alain Giorla. Light Water Reactor Sustainability Program Implementation of Concrete Creep Model in Grizzly. Technical report, Oak Ridge National Laboratory, November 2017. URL http://www.osti.gov/ scitech/.

Andrew T Godfrey, Benjamin S Collins, Kang Seog Kim, Rosemary Montgomery, Jeffrey J Powers, William A Stimpson, Shane G andWieselquist, Kevin T Clarno, Jess C Gehin, Scott Palmtag, Robert Montgomery, Dan Jabaay, Brendan Kochunas, Thomas Downar, Nathan A Capps, and Jeffrey Secker. VERA Benchmarking Results for Watts Bar Nuclear Plant Unit 1 Cycles 1-12. Technical Report CASLU-2015-0206-000, CASL, June 2016.

H. Graves, Y. Le Pape, D. Naus, J. Rashid, V. Saouma, A. Sheikh, and J. Wall. Expanded Material Degradation Assessment (EMDA), Volume 4: Aging of Concrete. Technical Report NUREG/CR-7153, ORNL/TM-2011/545, U.S. Nuclear Regulatory Commission, 2014.

B.S. Gray. The Effects of Reactor Radiation on Cement and Concrete. In Proceedings of an Information Exchange Meeting on 'Results of Concrete Irradiation Programmes', volume EUR $4751 \mathrm{f}-\mathrm{e}$, Brussels, Belgium, April 19 1971. Commission des Communautés Européennes.

H.K. Hilsdorf, J. Kropp, and H.J. Koch. The Effects of Nuclear Radiation on the Mechanical Properties of Concrete. Special Publication of The American Concrete Institute, 55:223-254, 1978.

R.J. Janowiak, H.G. Ashar, C.J. Hookham, and C.A. Zalesiak. ACI 349.3R-02: Evaluation of Existing Nuclear Safety-Related Concrete Structures. Technical report, American Concrete Institute, reapproved 2010.

D. Kambayashi, S. Sasano, H. Sawada, K. Suzuki, and I. Maruyama. Numerical Analysis of a Concrete Biological Shielding Wall under Neutron Irradiation by 3D RBSM. Journal of Advanced Concrete Technology, 18:617-632, 2020.

Y. Khmurovska, P. Štemberk, T. Fekete, and T. Eurajoki. Numerical Analysis of VVER-440/213 Concrete Biological Shield under Normal Operation. Nuclear Engineering and Design, 350:58-66, 2019.

Brendan Kochunas, Benjamin Collins, Shane Stimpson, Robert Salko, Daniel Jabaay, Aaron Graham, Yuxuan Liu, Kang-Seog Kim, William Wieselquist, Andrew Godfrey, Kevin Clarno, Scott Palmtag, Thomas Downar, and Jess Gehin. VERA Core Simulator Methodology for PWR Cycle Depletion. Nuclear Science and Engineering, 186:217-231, 2017. 
G. J. Kommendant, M. Polivka, and D. Pirtz. Study of Concrete Properties for Prestressed Concrete Reactor Vessels, Final Report - Part II, Creep and Strength Characteristics of Concrete at Elevated Temperatures. Technical Report no. UCSESM 76-3, University of California, Berkeley, 1976. prepared for General Atomic Company.

Y. Le Pape. Structural Effects of Radiation-Induced Volumetric Expansion on Unreinforced Concrete Biological Shields. Nuclear Engineering and Design, 295:534-548, 2015.

A.V. Luikov. Systems of Differential Equations of Heat and Mass Transfer in Capillary-Porous Bodies (Review). International Journal of Heat and Mass Transfer, 18:1-14, 1975.

C.E. Majorana, V.A. Salomoni, and B.A. Schrefler. Hygrothermal and Mechanical Model of Concrete at High Temperature. Materials and Structures, 31:378-386, 1998.

J. Mazars and G. Pijaudier-Cabot. Continuum Damage Theory -Application to Concrete. Journal of Engineering Mechanics - ASCE, 115:345-365, 1989.

J. Mazars, F. Hamon, and S. Grange. A New 3D Damage Model for Concrete under Monotonic, Cyclic and Dynamic Loadings. Materials and Structures, 48:3779-3793, 2015.

Jacky Mazars. Application de la mécanique de l'endommagement au comportement non linéaire et à la rupture du béton de structure. PhD thesis, Université Paris 6, France, 1984.

Jacky Mazars. A description of micro- and macroscale damage of concrete structures. Engineering Fracture Mechanics, 25(5-6):729-737, 1986. ISSN 00137944. doi: 10.1016/0013-7944(86)90036-6.

D.C. McDowall. The Effects of Gamma Radiation on the Creep Properties of Concrete. In Proceedings of an Information Exchange Meeting on 'Results of Concrete Irradiation Programmes', volume EUR 4751 f-e, pages 55-69, Brussels, Belgium, April 19 1971. Commission des Communautés Européennes.

Somayehsadat Mirhosseini, Maria Anna Polak, and Mahesh Pandey. Nuclear Radiation Effect on the Behavior of Reinforced Concrete Elements. Nuclear Engineering and Design, 269:57-65, 2014. ISSN 0029-5493.

S.S. Mirhosseini. The Effects of Nuclear Radiation on Aging Reinforced Concrete Structures in Nuclear Power Plants. PhD thesis, University of Waterloo, Ontario, 2010.

W. Nechnech, F. Meftah, and J.M. Reynouard. An Elasto-Plastic Damage Model for Plain Concrete Subjected to High Temperature. Engineering Structures, 24:587-611, 2002.

S. Palmtag and A. T. Godfrey. VERA Common Input User Manual. Technical Report CASL-U-2014-0014002, CASL, February 2015.

T. Pandya, T. Evans, K. Royston, K. Clarno, B. Collins, S. Stimpson, and S. Henderson. VERAShift User's Manual. Technical Report CASL-U-2019-1921-000, CASL, January 2020.

Cody J. Permann, Derek R. Gaston, David Andrš, Robert W. Carlsen, Fande Kong, Alexander D. Lindsay, Jason M. Miller, John W. Peterson, Andrew E. Slaughter, Roy H. Stogner, and Richard C. Martineau. MOOSE: Enabling massively parallel multiphysics simulation. SoftwareX, 11:100430, January 2020.

B. Pomaro, V.A. Salomoni, F. Gramegna, G. Prete, and C.E. Majorana. Radiation Damage Evaluation on Concrete within a Facility for Selective Production of Exotic Species (SPES Project), Italy. Journal of Hazardous Materials, 194(0):169-177, 2011. ISSN 0304-3894. 
R. J. McConn Jr. et al. Compendium of Material Composition Data for Radiation Transport Modeling. Technical Report PNNL-15870 Rev. 1, Pacific Northwest National Laboratory, 2011.

I. Remec. Radiation Environment in Concrete Biological Shields of Nuclear Power Plants. Light Water Reactor Sustainability Program, 2013.

I. Remec, T.M. Rosseel, K.G. Field, and Y. Le Pape. Characterization of Radiation Fields in Biological Shields of NPPs for Assessing Concrete Degradation. In Proceedings of the Fifteenth International Symposium on Reactor Dosimetry, Aix-en-Provence, France, May 18-23 2014.

V.A. Salomoni, C.E. Majorana, B. Pomaro, G. Xotta, and F. Gramegna. Macroscale and Mesoscale Analysis of Concrete as a Multiphase Material for Biological Shields against Nuclear Radiation. International Journal for Numerical and Analytical Methods in Geomechanics, 38:418-535, 2014.

Larry A. Schoof and Victor R. Yarberry. Exodus II: a Finite Element Data Model. Technical Report SAND92-2137, Sandia National Laboratories, September 1994.

B.A. Schrefler, L. Simoni, and C.E. Majorana. A General Model for the Mechanics of Saturated-Unsaturated Porous Materials. Materials and Structures, 22:323-334, 1989.

B. W. Spencer, M. Backman, P. Chakraborty, D. Schwen, Y. Zhang, H. Huang, X. Bai, and W. Jiang. Grizzly Usage and Theory Manual - Version 1.0 Beta. Technical Report INL/EXT-16-38310, Idaho National Laboratory, March 2016.

B. W. Spencer, W. M. Hoffman, S. Biswas, and A. Jain. Assessment of Grizzly Capabilities for Reactor Pressure Vessels and Reinforced Concrete Structures. Technical Report INL/EXT-20-59941, Idaho National Laboratory, September 2020.

Benjamin W. Spencer, William M. Hoffman, Benjamin S. Collins, and Shane C. Henderson. Use of Neutron Flux Calculated by Shift in a Grizzly Reactor Pressure Vessel Fracture Simulation. Technical Report CASL-U-2019-1898-000, CASL, September 2019.

Benjamin W. Spencer, William M. Hoffman, Sudipta Biswas, Wen Jiang, Alain Giorla, and Marie A. Backman. Grizzly and BlackBear: Structural Component Aging Simulation Codes. Nuclear Technology, 207 (7):981-1003, April 2021.

Jean Michel Torrenti and Robert Le Roy. Analysis of Some Basic Creep Tests on Concrete and Their Implications for Modeling. Structural Concrete, 19(2):483-488, 2018. ISSN 17517648. doi: 10.1002/ suco.201600197.

J. A. Turner, K. Clarno, M. Sieger, R. Bartlett, B. Collins, R. Pawlowski, R. Schmidt, and R. Summers. The Virtual Environment for Reactor Applications (VERA): Design and Architecture. Journal of Computational Physics, 326:544-568, December 2016.

M. Vandamme and F.-J. Ulm. Nanogranular Origin of Concrete Creep. Proceedings of the National Academy of Sciences, 106(26):10552-10557, 2009.

F. Vecchio and M.P. Collins. The Response of Reinforced Concrete to In-Plane Shear and Normal Stresses. Technical Report 82-03, University of Toronto, 1982.

F.J. Vecchio and M.P. Collins. The Modified Compression-Field Theory for Reinforced Concrete Elements Subjected to Shear. ACI Journal, 83:219-231, 1986. 
J. C. Wagner and A. Haghighat. Automated Variance Reduction of Monte Carlo Shielding Calculations Using the Discrete Ordinates Adjoint Function. Nuclear Science and Engineering, 128(2):186-208, 1998.

John Wagner, Douglas Peplow, and Scott Mosher. FW-CADIS Method For Global And Regional Variance Reduction Of Monte Carlo Radiation Transport Calculations. Nuclear Science and Engineering, 176(1), January 2014. ISSN 00295639. doi: 10.13182/NSE12-33.

W. A. Wieselquist, R. A. Lefebvre, and M. A. Jessee. SCALE Code System. Technical Report ORNL/TM2005/39, Version 6.2.4, Oak Ridge National Laboratory, 2020.

Y. Xi, Z.P. Bažant, L. Molina, and H.H.M. Jennings. Moisture Diffusion in Cementitious Materials, Moisture Capacity and Diffusivity. Advanced Cement Based Materials, 1:258-266, 1994.

V G Zubov and A T Ivanov. Expansion of Quartz Caused by Irradiation with Fast Neutrons. Soviet Phys.Cryst. (Engl. Transl.), 11: 372-4(Nov.-Dec. 1966)., 1 1966a. URL https://www.osti.gov/biblio/4467429.

V.G. Zubov and A.T. Ivanov. Expansion of Quartz Caused by Irradiation with Fast Neutrons. Soviet Physics Crystallography, 11(3):372-374, 1966b. 



(n)

